\title{
Particle transport in gravel-bed rivers: revisiting passive tracer data
}

Authors: Daniel Vázquez-Tarrí01,2, *, Alain Recking3, Frédéric Liébault3, Michal Tal4 and Rosana Menéndez-Duarte2

1 INDUROT (Universidad de Oviedo), Campus de Mieres, s/n 33600 (Mieres)

2 Departament of Geology (University of Oviedo), c Jesús Arias de Velasco, s/n 33005 (Oviedo)

3 Univ. Grenoble Alpes, Irstea, UR ETGR, St-Martin-d'Hères, France

4 Aix Marseille Univ, CNRS, IRD, INRA, Coll France, CEREGE, Aix-en-Provence, France

*Corresponding author, email address: vazquezdaniel@uniovi.es

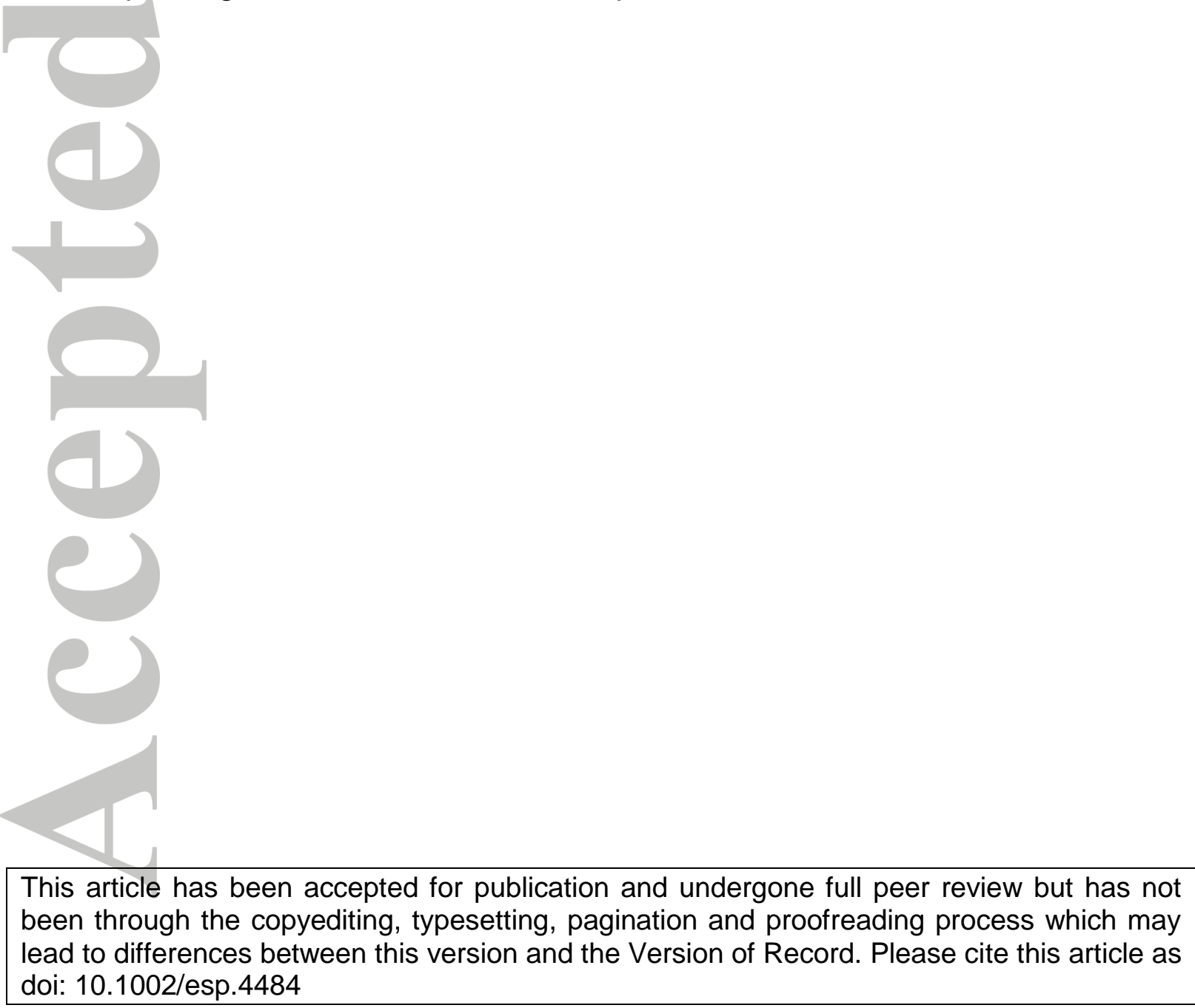

This article is protected by copyright. All rights reserved. 


\section{Abstract}

Data from tracer experiments were compiled and analysed in order to explore the role of geomorphological, hydrological and sedimentological constraints on fluvial gravel transport in gravel-bed rivers. A large data set from 217 transport episodes of tagged stones were compiled from 33 scientific papers. Our analyses showed that while magnitude of peak discharge is a major control on gravel transport and mobility, tracer travel distances show some scale dependence on the morphological configuration of the channel. Our results also highlight differences in the way tracers are displaced between step-pool and riffle and pool channels. The riffle-pool sequence seems to be a more efficient trap for travelling gravels than the step-pool pair. Additionally, in step-pool channels there are clear differences in tracer transport between observations of first displacements after tracer seeding (unconstrainedstone conditions), and second and subsequent observations of tracer displacements (constrained-stone conditions). The comparison between tracer experiments under constrained conditions and those under unconstrained ones also highlights the importance of bed state and structures in gravel mobility. The results of this study confirm that sediment transport in gravel-bed rivers is a complex process, whereby sedimentological and geomorphological controls are superimposed on the hydraulic forcing. 


\section{INTRODUCTION}

Sediment tracking using tagged stones placed in the streambed represents an interesting and relatively inexpensive source of information on sediment transport and dispersion in gravel-bed rivers. In this regard, tagged stones have been used to study flow competence and grain position relative to meso and micro bedforms (e.g. Laronne and Carson, 1976), particle entrainment (e.g. Hassan et al., 1992), constraints on sediment dispersion (e.g. Church and Hassan, 1992), virtual rates of sediment movement (e.g. Hassan et al., 1991), the distribution of periods of rest and movement during transport episodes (e.g. McNamara and Borden, 2004), the relationship between gravel dispersion and channel morphology (e.g. Milan et al., 2002; Milan, 2013b; Papangelakis and Hassan, 2016), sediment volumes carried during floods (e.g. Liebault and Laronne, 2008; Vázquez-Tarrío and MenéndezDuarte, 2014; 2015), bed material/bed load exchanges (e.g. Hassan and Church, 1994), and scour and fill depths (e.g. Haschenburger, 1999). According to Haschenburger (2013), similar observations cannot be collected using only laboratory flumes. Earlier tags consisted of painted stones (e.g. Laronne and Carson, 1976), inserted magnets (e.g. Hassan et al., 1984) or magnetically enhanced gravels (Sear, 1996). The recently developed method of inserting passive integrated transponders (PIT tags) into clasts and tracking them with a radio antenna (Nichols, 2004; Lamarre et al., 2005; Lamarre and Roy, 2008b; Schneider et al., 2010; Bradley and Tucker, 2012; Liébault et al., 2012; Olinde and Johnson, 2013; Phillips et al., 2013), has reduced some of the problems associated with previous passive tracer techniques, including low recovery rates and the problem of buried tracers and decaying labels (Hassan and Bradley, 2017). More recently, active tracking methods have been shown to be very promising in terms of expanding the 
tracer method to larger river systems than those typically studied with passive tracers (Cassel et al., 2017). Owing to these advances, sediment tagging has become a common technique in geomorphological studies.

The particle tracing method enables tracking the movement of individual stones on the streambed. Indeed, it is the only suitable field method providing information about particle paths and patterns of bed load dispersion in natural streams. One of the most widely explored issues using tracers has been the downstream displacement of fluvial gravels (e.g., Church and Hassan, 1992; Haschenburger, 2011). Several studies have used tracer data in order to establish functional relationships between tracer travel distances and flow magnitude (e.g. Hassan et al., 1991; Schneider et al., 2014; Houbrechts et al., 2015). Other studies (Milan et al., 2002; Pyrce and Ashmore, 2003a, b; 2005; Liebault et al., 2012; Milan, 2013b) have examined the control exerted by macroforms and channel morphology on tracer dispersion in bar-pool channels. In the same vein, a recent study by Papangelakis and Hassan (2016) analysed the role played by different channel morphologies on tracer displacement in the gravel-bed East Creek (Canada) using a 10-year tracer dataset. In addition, re-examination of compiled tracing data highlighted relationships between tracer travel distance and grain size, duration of competent flow and tracer dispersion, dispersal velocity and excess stream power, mean travel distances and flow magnitude, and the distributions of travel distances and burial depths (Hassan et al.,1991; Church and Hassan 1992; Hassan and Church, 1992; Haschenburger,2013; and Milan, 2013a). Hassan and Bradley (2017) also stated the constraining effect played by bed texture and particle arrangements on particle displacement. 
These previous studies helped establish hydraulics as a major forcing on fluvial gravel transport. However, an important amount of variance in available tracer data remains unexplained (Hassan and Bradley, 2017), suggesting the influence of controls other than flow magnitude on tracer displacement, for example bed state or channel morphology (Papangelakis and Hassan, 2016; Hassan and Bradley, 2017). However, the function played by sediment texture and channel morphology on bed sediment transport is difficult to quantify using only the results from a single tracer experiment due to the complex interactions between bed morphology, surface sediment and flow (Hassan and Bradley, 2017). The goal of this study was to investigate hydraulic, textural, and geomorphological constraints on downstream transport of fluvial gravels using a sufficiently large data set that would permit to discus and compare data from a wide diversity of mountain rivers. In order to do this, we compiled and analysed a large data set based on 217 passive tracer experiments reported in 33 previously published studies.

In-depth reviews of the gravel tagging have been published by Sear et al. (2000), Hassan and Ergenzinger (2003), Hassan and Roy (2015) and Hassan and Bradley (2017). The present study presents novel analyses of the data not considered in the previous studies. First, in order to improve our understanding of links between channel style and sediment transport in gravel-bed streams, we relate tracer travel distances to average spacing between morphological units (e.g., step-pool, bar-bar, pool-pool spacing in each case). In this sense, Beechie (2001) already observed an association between travel distance and channel width in tracer studies, suggesting that channel width appear to drive tracer transport as far as it also controls bar spacing. Later, Pyrce and Ashmore (2003a, b; 2005) showed how during channel forming-flows in gravel bed rivers, the path length of transported particles must be 
equal to the morphological length scale of channel. Milan et al. (2002) and Milan. (2013b) reported that channel morphology in pool-riffle channels influenced travel paths of tagged stones while Gintz et al. (1996) and Lamarre and Roy (2008b) investigated the role of step-pool morphology in gravel transport. Other works also showed how mean distance of travel of tracer stones is controlled by the average spacing of macroforms (e.g. Hassan et al., 1991; Liebault et al., 2012). Recently, Recking et al. (2016) also identified differences between bed load transport in different channel settings and suggested a 'morphological imprint' of bed load processes and, thus an interest in studying the links between channel morphology and particle pathways in mountain rivers. In this present study, we explore the relationship between channel style and sediment displacement in detail, with a particular focus on differences between riffle and pool and step-pool channels. We also consider separately data of tracer displacements immediately after tracer seeding, referred to as 'unconstrained-stone' experiments, and data from second and subsequent tracer displacements, wherein tagged stones are considered to be 'constrained' by bed structures (herein referred to as 'constrained-stone' experiments). Brayshaw et al. (1983), Reid et al. (1992), Powell and Ashworth (1995) and Church et al. (1998) pointed to the control of particle arrangements and clusters on entrainment of individual tracer particles. In addition, Church and Hassan (1992) and Hassan et al. (1992) highlighted the difficulty of isolating the sizedistance problem from particle entrainment in tracer experiments where tagged stones are constrained in the bed. However, to our knowledge, no explicit comparison between these two different experimental conditions has been made in preceding assessments of tracer data. Finally, we analysed the fraction of mobile tracers and how it evolved with flow magnitude and duration. By considering the 
fraction of mobile tracers together with the analysis of tracer travel distances, we sought to maximize the information that could be obtained from available tracer data with respect to two of the main controls on bed load transport: surface bed mobility and downstream transport of riverbed gravels.

This study builds on our understanding of the geomorphologic and hydrological controls on sediment transport and contributes in two important ways to the previous reviews of tracer studies cited earlier. One is the explicit comparison between 'constrained-' and 'unconstrained-' stone experiment conditions, which provides interesting insights into the influence of different channel morphologies on the way tracer stones are conveyed downstream in steep, mountain channels. The other concerns the analysis of the influence of antecedent, subthreshold flow on tracer dispersion.

\section{MATERIALS AND METHODS}

\section{Data set compilation}

The data set used in this paper is comprised of results from 217 passive tracer experiments carried out in 30 gravel bed rivers in various locations and published in 33 scientific papers between 1970 and 2016 (Table 1). Data are derived from field experiments using painted, magnetically and PIT tagged stones. They cover a wide range of channel styles, morphologies and bed textures. The data come from studies spanning a wide range of hydrological regimes, from ephemeral streams in arid regions to perennial streams with gradually varied glacio-nival hydrological regimes.

We compiled the following information for each of the data sets: a. general information describing the study reaches (channel width, channel slope, channel morphology, grain size of surface sediment, hydrological regime), b. information about the tracer experiments (tracing method, peak discharge of the studied 
transport episodes, recovery ratios, percentage of mobilized particles, mean and maximum travel distances), c. information on flow duration of the transport episodes (including number of peaks of flow) and the number of antecedent days, where available, and $\mathrm{d}$. whether the data was from first (unconstrained) displacements or second or later (constrained) displacements after tracer seeding. For the unconstrained data, special care was taken to only consider the actual data from first displacements after tracer seeding. Some studies did not report these first tracer movements in order to allow particles to become incorporated into the bed structure. In such cases, the first reported movements were obviously classed as constrained data.

Some of the above information was explicitly mentioned in the papers; and some could be inferred from graphs and figures (Table 1). The compiled data was grouped by channel style: riffle and pool (RP), step-pool (SP), plane-bed (PB) and multithread (MT) channels (Montgomery and Buffington, 1997).

\section{Overview of compiled data}

In terms of tracer type, the compiled data consists of $51 \%$ of points from experiments using PIT tags, and $13 \%$ and $36 \%$ respectively from experiments using painted stones and clasts with inserted magnets. Time trends in the utilized technique show a progressive shift from painted clasts toward magnets and PIT tags: earlier experiments (1960s - 1980s) used only painted stones; magnetically tagged stones were introduced in the 90s. PIT tags became the predominant method in the past decade. Average tracer recoveries are $81 \%$ and $71 \%$ respectively for PIT tags and magnets. They are considerably lower for painted stones, 58\%, highlighting the poorer performance of this method compared to magnets and PIT tags which allow the retrieval of buried tracers. Tracer recoveries are comparable for inserted 
magnets and PIT-tags, suggesting that both strategies provide similar results. However, magnets have two disadvantages when compared to PIT tags: i. magnetically tagged clasts need to be dug out (i.e. physically recovered) in order to be identified, and this may disturb bed structure (Hassan et al., 1984); and ii. they have a problem of decaying labels (Vázquez-Tarrío, 2013; Hassan and Bradley, 2017).

With regard to channel morphology, the data correspond to $58 \%$ RP channels, $31 \%$ SP channels, 9\% PB channels and $2 \%$ multithread (MT) channels. Average tracer recoveries are similar for $\mathrm{RP}(68 \%)$ and SP systems $(73 \%)$. The slightly larger average recovery ratio for the SP group of data is likely explained by a larger percentage of experiments using PIT-tags in SP (53\%) than in RP data sets (47\%). In order to avoid methodological biases in our analyses linked to differences in performance based on tracer type, we decided to focus only on those experiments for which tracer recoveries exceeded $75 \%$. In addition, we excluded a few study cases in which the maximum distance of travel was not adequately surveyed.

\section{Exploratory analysis of compiled data set}

The first part of the data analysis was aimed at determining how much of the variance in data on tracer mobility and displacement could be explained by hydraulic forcing. The magnitude of tracer transport was determined from the mean travel distances of each tracer population. The degree of tracer mobility was computed using the fraction of mobile tracers: the ratio between the number of tracers that moved and the total number of tracers recovered. We chose to use specific stream power to characterise the flow magnitude of each transport episode. Stream power has been traditionally used in tracer studies (for example, Hassan et al., 1992; Lamarre and Roy, 2008b; Schneider et al., 2014; Papangelakis and Hassan, 2016) 
most likely because estimating reach-averaged flow depth is difficult in steep mountain streams owing to the strong influence of local roughness elements on the water surface (Eaton and Church, 2011; Schneider et al., 2014), and the fact that discharge is more readily available (Rickenmann and Recking, 2011). It also avoids the need to compute flow resistance. Eaton and Church (2011) and Diplas et al. (2016) proposed a dimensionless version of unit stream power, obtaining stronger scaling relationships between bed load and flow magnitude than those obtained using the dimensional form. We decided to use the non-dimensional version of stream power defined by Eaton and Church (2011) in order to avoid scale differences between the different study cases:

$$
\omega^{*}=\frac{\omega}{\rho \cdot(g \cdot R \cdot D)^{3 / 2}}
$$

where $\omega^{*}$ is the dimensionless stream power, $\omega$ is peak unit stream power (Bagnold, 1966; 1980) computed based on reported peak discharge data, $R$ the submerged specific weight of sediment and $D$ a representative grain size for the bed surface for which we used the median bed surface size $\left(D_{50}\right)$.

To account for a likely dependence of tracer transport on channel morphology, we normalized tracer travel distance by what we called the 'morphological length scale' of channel, i.e., an approximate measure of the spacing between macroforms. In RP channels, pool-pool or riffle-riffle spacing is typically 5 to 7 times, and on average 5.7 times the channel width (Montgomery and Buffington, 1997). As such, we normalized tracer travel distances by 5.7 times the channel width for RP derived data. In SP channels, spacing between two step-pool units depends on several variables including slope (Church and Zimmerman, 2007) and is therefore only partially scaled with channel width. We used the formula presented by Abrahams et al. (1995) (Eq. 
2). Recking et al. (2012) found output from this formula to be in good agreement with measured step-pool dimensions of 42 studied reaches in the French Alps and Vosges Mountains. It links step-pool spacing to step-heights and channel slope:

$$
L=1.493 \cdot H^{1.011} \cdot S^{-0.682}
$$

where $L$ is step-pool spacing, $H$ the step-height and $S$ channel slope. We approached step-height through the $D_{84}$ of bed surface sediment. In multithread channels the definition of a morphological length scale is not as straightforward as in single-thread systems. In these settings, particle travel distances may scale with average bar spacing (Hundey and Ashmore, 2009). Hundey and Ashmore (2009) and Kasprak et al. (2015) observed that a confluence or diffluence occurs approximately once every 5.2 channel widths in braided rivers, consistent with the average pool spacing (5-7 channel widths) in many single-thread RP channels. We therefore used this value of 5.2 times the channel width for the MT data. Finally, in plane-bed (PB) channels, tracer travel distances were normalized directly by channel width. This normalization of tracer transport distances by morphological length scale was aimed at determining whether dispersed tracers travel further than one morphological channel-unit. It also serves as a basis for exploring how morphological units control the transport of gravels and the potential differences in downstream particle transport between different channel styles.

After considering the impact of flow magnitude on tracer transport/mobility, we proceeded to analyse the influence of hydrological controls, mainly the time duration of competent flow and the amount of time passing between tracer seeding and tracer dispersion. For some of the compiled tracer experiments (34 of 78 selected data points), the original study provided information about the flow duration above the critical threshold of sediment motion, allowing us to assess whether flow duration 
was correlated with the percentage of mobile tracers. In some cases, information was also available about the time that elapsed between tracer seeding and the subsequent competent flow, or between two successive transport episodes (27 of the 78 selected points). We used this information to explore whether antecedent, sub-threshold flows had an influence on tracer travel distances and the percentages of moving tracers.

In all the analyses, we considered separately unconstrained and constrained-stone conditions. In the first kind of data, tracer stones are free compared to constrained conditions where they are arranged on the bed. Downstream tracer displacement was thus only dependent on absolute size effects in the former, whereas in the latter downstream tracer travel depends on both size as well the ability of the flow to breakup bed texture and particle arrangements. Re-entrainment of previously buried tracers may also play a role on constrained-stone data.

\section{RESULTS}

\section{Influence of flow magnitude on downstream tracer transport}

We found a weak positive power correlation $\left(R^{2}=0.25\right.$, $p$-value $\left.=0.00<0.05\right)$ between tracer travel distance and non-dimensional stream power (Figure 1). In general, $R^{2}$ increased when we split our data amongst the different channel styles and between constrained and unconstrained data (Table 2). For equivalent hydraulic inputs, sediment is thus transported further during unconstrained experiments in SP channels (Figure 2A). In PB channels, sediment displacement is on average one order of magnitude lower than in SP and/or RP channels (Figure 1). In RP channels, data are segregated according to the width / bankfull depth ratio $(W / d)$, with larger tracer transport distances in wider channels (W/d>10; Figure 2B); in narrow channels, distances of transport are one order of magnitude lower and comparable 
to PB systems. Differences between narrow and wide channels are statistically significant at a 95\% confidence-level (ANCOVA test, $p$-value<0.05).

The $R^{2}$ increases in the SP sub-data set when we consider separately constrained and unconstrained experiments (Figure 2A). These differences are once again statistically significant (ANCOVA test, $p$-value $<0.05$ ). However, there are no differences between the experimental conditions in the case of RP and PB channels (ANCOVA test, $p$-value>0.05). In addition, RP data tend to plot over SP data in constrained experiments (Figure 1), even though there is an important amount of overlap between both groups of data (particularly at large values of excess stream power). The different behaviour between both experimental conditions in SP and RP data suggest some influence of entrainment on tracer transport in the former that is lacking in RP channels: larger scale of macroroughness elements in SP channels may involve higher friction losses by form effects, and consequently a loss of entrainment efficiency for equivalent excess stream powers.

However, the observed differences between different channel styles and experimental conditions could be biased by differences in flood hydrographs (Comitti, in: Hassan and Bradley, 2017). Shorter duration, flashy hydrographs may involve lower tracer transport than long, sustained floods. Unfortunately, information about flow duration was reported for relatively few of the data compiled. We estimated virtual velocities (tracer travel distance / flow duration) for these cases (Figure 3). However, the data are very scattered and do not show statistically significant correlations (Figure 3). Virtual velocities are probably more linked to timeintegrated rather than to peak stream power (Haschenburger, 2013; Schneider et al., 2014; Klösch and Habersack, 2018), and this may partially explain the strong scatter. There is also the problem of how to define the actual duration of competent flow. The 
information provided consisted normally in calendar time above a competence threshold defined for the entire bed (e.g. Gintz et al., 1996; Ferguson and Wathen, 1998; Haschenburger and Church, 1998; Bradley and Tucker, 2012; Vázquez-Tarrío and Menéndez-Duarte, 2014; Dell'Agnese et al., 2015), rather than using a grainsize based competence threshold as proposed by Milan (2013a) and Klösch and Habersack (2018). Nevertheless, the trends in figure 3 are comparable to those seen previously for tracer distances. Differences between constrained and unconstrained conditions are only present in SP data. In addition, unconstrained SP data project over RP plots, suggesting that sediment travel farther and faster during unconstrained experiments in SP channels for equivalent hydraulic inputs. Furthermore, it seems that in RP channels there are no differences between transport episodes that are only dispersing surface sediment (equivalent to unconstrained conditions) and episodes that reorganize bed sediment texture (equivalent to constrained conditions). Conversely, in SP channels, significant, faster and further sediment displacement is possible without bed sediment disorganization, seen by comparing unconstrained and constrained experiments in figure 2 and constrained and unconstrained experiments in figure 3. Based on the weak correlation between virtual velocity and peak stream power showed in figure 3 , one could also argue that virtual velocity is roughly independent of stream power, particularly in SP constrained data (Figure 3). This may be related to the fact that strongest flows (in terms of peak stream power) use to last longer: this may partially counter the effects of increasing larger transport distances with increasing peaks of flow. This outlines the need to consider explicitly the influence of flow duration isolated from stream power in our analysis (see below in the text).

\section{Influence of channel morphology on downstream tracer transport}


In figure 4, tracer travel distances are divided by the estimated spacing between macroforms. In doing so, we see a stronger correlation between tracer travel distance and stream power (Table 2). This suggests some dependence of tracer movement on channel morphology. However, the most important information provided by this plot concerns differences between SP and RP channels in the way tracers are conveyed downstream. According to figure 4, tracer transport does not normally exceed by much one morphological unit (i.e. one riffle-pool sequence) in RP channels and it rarely reaches five morphological lengths, whereas in SP systems tracers can be easily exported out from one single step-pool unit. The differences between the channel morphologies are statistically significant (ANCOVA test, $p$-value<0.05). We also evaluated the data in terms of flow recurrence, using the ratio of the discharge for the transporting episode to the bankfull discharge (Figure 5). Sediment does not travel further than one morphological unit during flows approaching bankfull in RP channels. In SP and PB channels, considerable tracer displacement is possible during flows below bankfull discharge, with clear differences between constrained and unconstrained cases in SP data: thus, gravels are transported downstream in SP systems more readily when the surface texture of the bed is disturbed (i.e. unconstrained vs constrained conditions, figure 5).

The weak differences observed between constrained and unconstrained conditions in RP channels seems to contradict a large body of literature showing how tracers slow-down with time (e.g. Ferguson and Wathen, 1998; Ferguson and Hoey, 2002; Ferguson et al., 2002; Bradley and Tucker, 2012; Haschenburger, 2011; Houbrechts et al., 2011; Klösch and Habersack, 2018). For this reason, we decided to analyse with more detail the compiled data. We classified RP data according to 'tracer age': the number of years passing since tracers were seeded (figure 6). We observed that 
'older' tracer data (>5 yrs) tend to plot in the lower envelope of the point cloud in figure 6, whereas 'younger' tracer data ( $<2$ yrs plus unconstrained data) tend to plot in the upper envelope. Indeed, unconstrained data tend to overlap with tracers 'younger' than 3 years, but not with 'older' tracers. This observation may suggest that unconstrained and young constrained tracers have a comparable behaviour, while different behaviour appear between unconstrained and 'old' constrained data. All this indicates that the energy needed to displace tracers increase with 'tracer age' and is in good agreement with previous findings suggesting that tracer dispersion slows down with time (Ferguson and Wathen, 1998; Ferguson and Hoey, 2002; Ferguson et al., 2002). This slowdown may be a consequence of particle trapping and burial (Hassan and Church, 1994; Haschenburger, 2011; Hassan and Bradley, 2017), and according to our results it seems to need some time before tracers become thoroughly mixed into the bed (>3-4 years).

\section{Influence of tracer size on downstream tracer transport}

It has been near universally observed in tracer studies that smaller particles show larger displacements than larger particles (e.g. Church and Hassan, 1992; Hassan and Church, 1992; Ferguson and Wathen, 1998; Schneider et al., 2014). After Church and Hassan (1992) and Hassan and Church (1992) it is well stated that grain size plays a role in downstream transport distance of particles coarser than the median grain size of the bed surface, with tracer travel distances decreasing strongly with particle size at these coarser terms of the grain size distribution.

In figure 7 we have plotted mean tracer travel distance, scaled by the mean distance of travel of the median size class of surface sediment $\left(L^{*}\right)$, against the ratio between tracer size and the median size of the subsurface grain size distribution $\left(D^{\star}\right)$. For this plot, we have used the large data set employed by Hassan and Bradley (2017) (after 
Church and Hassan,1992), and we have incorporated new data compiled for the present research (Dudley, 2007; Liébault et al., 2012, Milan, 2013b; Schneider et al., 2014; Papangelakis and Hassan, 2016; and Mao et al., 2016). The new data add some scatter to the original data set of Hassan and Bradley (2017), but the plot continue to follow the general relation between tracer travel distance and tracer size proposed by Church and Hassan (1992) and Hassan and Church (1992). The best regression fit that we have found for the data shown in Fig. 7 is:

$\log L^{*}=-0.21 \cdot D^{*}+0.26$

$\left(n=702, p<0.001, R^{2}=0.272\right)$.

This regression equation follow a similar convex-up shape and only deviate to a small extent from Church and Hassan's (1992) curve: it plots slightly above for the coarser grain sizes, and slightly below for the finer ones. Furthermore, our curve is very close to that from Milan (2013a) for those grain sizes below the median size of the bed material. Both our curve and the fit found by Milan (2013a) fall in general between the $95 \%$ - confidence bonds of Church and Hassan (1992) and they show a similar size-selective behaviour: travel distance drops off rapidly for tracer grain sizes progressively coarser than the $D_{50}$ of the bed material. In addition, the data from the different channel settings overlap strongly: this size-selective behaviour seems to be independent from the channel morphological style.

If tracer travel distances depend on tracer size relative to bed sediment, then some of the differences amongst PB, SP and RP data shown in the previous section could be biased by differences in tracer sizes. In order to address this issue, we looked at the relative size of tracers in relation to bed surface for the different group of data (figure 8) and we observed three things: i. in general, many tracer studies use the surface $D_{50}$ size-class as a reference for choosing the median size for the tracer 
population; ii. in some RP and PB data, median tracer size is below surface $D_{50 .}$, which may contribute to larger displacements for the RP and PB data rather than the opposite trend observed in figure 4; and iii. tracer size relative to bed surface for constrained and unconstrained studies are comparable in the SP data set, so differences in tracer distances between both conditions are not explained by differences in tracer size. These three observations points out in the same direction as the results shown in figures 4 and 5 and confirm that tracer size was not a bias: gravels tend to travel across more morphological units in SP than in RP channels for similar hydraulic inputs, and this tendency is not dependent on the particle size.

\section{Influence of flow duration and antecedent flow on tracer transport}

While it seems obvious that a higher duration of competent flow would result in larger cumulated travel distances, differences may exist between channel style and / or experimental conditions. In order to deal with this issue, prior to analysing the effects of flow duration, we isolated the actual influence of duration of competent flow from the confounding effects of flow magnitude. We did this by estimating the ratio between stream power and tracer travel distance. This ratio is a proxy of the amount of energy expenditure needed to displace tracers one meter. Figure 9 shows this ratio plotted versus flow duration. The results suggest that the amount of energy required to displace tracers decreases with flow duration: increases in flow duration increment the time available to displace tracers a certain distance, and thus reduces the need for higher flow peaks. However, differences exist based on experimental conditions: for equivalent flow durations, tracer transport requires less energy expenditure under unconstrained conditions in SP channels. In addition, the slope of the plot is steeper suggesting a larger increase in tracer displacements with flow duration in unconstrained conditions. 
In order to assess the influence of antecedent sub-threshold flow on tracer transport, we analysed all available data on how much time had passed between tracer seeding and the subsequent competent flow and/or between the considered and the preceding transport episode. As in the case of flow duration, we isolated the actual influence of antecedent time from the confounding effects of flow magnitude by plotting the ratio between stream power and tracer travel distances (times the duration of competent flow) against antecedent time. The plot (figure 10) shows how the length of antecedent time increases the amount of energy expenditure. This result suggests that interflood sub-threshold flows may play a role in enhancing particle arrangements and clast stability. This may include agitation and pivoting which contribute to stabilize clasts and moving free particles to protected positions in the channel.

\section{Tracer mobility}

Despite the huge amount of scatter, the percentage of mobile tracers has a weak tendency to increase with stream power (at least for SP and PB data) (Figure 11A). PB- and constrained SP-data tend to plot in the right side of the figure $11 \mathrm{~A}$, suggesting that bed disorganization requires larger hydraulic inputs in these channels. Lower stream powers are needed in the SP-unconstrained case to achieve similar percentages of tracer mobility as those observed in equivalent constrained experiments. RP data show a very large scatter and no clear link between stream power and percentages of mobile tracers.

The strong scatter of figure $11 \mathrm{~A}$ suggest that tracer mobility may be dependent on other hydrological constraints, for example flow duration. In figure 11B, the ratio between non-dimensional stream power and percentage of mobile tracers - a proxy of the amount of energy needed to displace a certain number of tracers - is plotted 
versus flow duration. This avoids the problem of comparing the influence of flow duration with data submitted to different flow conditions. Figure 11B shows that: i. this ratio is higher for constrained compared to unconstrained conditions; and ii. the ratio decreases more strongly with flow duration under unconstrained conditions in SP channels as compared to constrained conditions (exponent of the power regression equation is double in constrained than in unconstrained SP data: -0.22 vs -0.11 ). In other words, when the tracers are unconstrained, flow duration contributes to a certain amount of increase in percentages of mobile tracers because more time is available to displace the tracer population. Conversely, in constrained cases, the effect of an increase in flood duration is buffered by the need for some of this energy to be expended on disorganizing bed structures before tracers can be dispersed.

Figure 12 plots the percentages of mobile tracers versus the ratio of the discharge of the transport event to bankfull discharge. In RP channels there is a clear trend between flow magnitude and tracer mobility. In SP data there are differences between constrained and unconstrained conditions: $80-100 \%$ tracer mobility can be achieved by flow discharges lower than bankfull in SP unconstrained cases; for constrained conditions, $80-100 \%$ tracer mobility occurs at flow discharges around 2 times bankfull discharge while flows close to bankfull are characterised by less than $50 \%$ tracers in motion, and this is similar for SP and RP data. The results highlight the role of bed texture in constrained conditions and underscore two main points: i) the degree of tracer perturbation in SP during floods depends not only on flow magnitude, but also on the degree of tracer stabilization by particle arrangements and bed texture; and ii) the dominance of partial mobility over full mobility conditions in the available database of tracer experiments.

\section{DISCUSSION}




\section{Influence of flow magnitude: potential sources of scatter in the data}

Flow discharge is a major control on gravel transport. Stream power explained more than half of the variance in our data when adequately grouped according to a geomorphological criterion and experimental conditions (Table 2). Comparable correlations between tracer travel distance and flow discharge have been found previously by, amongst others, Hassan et al. (1992), Schneider et al. (2014) and Houbrechts et al. (2015).

Concerning tracer mobility, we found a positive increase in the percentage of mobile tracers with flow magnitude; a comparable result was found by Phillips and Jerolmack (2014) or Papangelakis and Hassan (2016). Based on our analysis, high percentages of mobile tracers (exceeding 70\%) in constrained experiments are only achieved during flows $1.5-2$ times the bankfull (Figure 12), suggesting that partial mobility conditions dominate during more frequent floods, and that stable areas in the bed surface will persist from year to year. Similar results were found by Haschenburger and Wilcock (2003) in Carnation Creek: they found that only $20-50 \%$ of the bed surface was active for floods with a 2-year recurrence interval and that full mobility only occurred for floods with a 7-year recurrence interval.

The correlation between peak stream power and tracer transport found here, as well as in previous works (e.g., Hassan et al., 1992; Schneider et al., 2014), while statistically significant, shows strong scatter. This indicates that a large amount of variance in the data cannot be explained by flow discharge alone, prompting us to explore other potential controls. One such control was methodological uncertainties. For example, we used peak discharge in order to estimate stream power. However, stronger correlations may be found using stream power or discharge integrated over time (Haschenburger, 2013; Phillips et al., 2013; Schneider et al., 2014). 
Unfortunately, the compiled papers provide rarely this information and using peak discharge was the only possibility for performing a homogenous analysis of all the compiled data. Furthermore, little information was provided in the original studies concerning the manner in which tracer distances were measured. Over the past decade, the use of highly accurate geolocalization devices (dGPS, Total Station...etc) have become standard practice amongst geomorphologists and in tracer studies (e.g., Liebault et al., 2012). However, in older tracer studies (e.g., Haschenburger, 1996; Haschenburger and Church, 1998), tracer travel distances were recorded using a tape measure running the length of the study reach. Another problem may be related to cross-sectional sediment dispersion. In this study, the focus was on transport of fluvial gravels in the downstream direction. However, a lateral or cross-sectional component for gravel displacement may exist (Dietrich and Smith, 1984; Seizilles et al., 2014). As a result, sediment displacements may be underestimated in some cases, particularly in morphological settings where there are no topographical constraints to bed load conveyance, (e.g., plane-bed channels). Hardly any information about this cross-sectional particle shift could be found in the published studies. Yet another potential methodological constraint not considered here was the influence of the location of tracer seeding. In RP channels, Sear (1996) reported that travel distances were larger for tracers seeded on pool heads and tails compared to those seeded on riffles. Milan et al. (2002) and Milan (2013b) observed how tracers tend to follow streamlines and that those tracers seeded on riffles do not appear to be routed into pools. Likewise, Liébault et al. (2012) observed higher tracer mobility for tracers deployed in the low-flow channel than on gravel bars. We can therefore expect important differences in tracer dispersion depending on where the tracers were deployed, introducing an important source of scatter in data. Once 
again, this information is not typically provided in the original studies and is therefore difficult to assess. Potential sources of variance in the data related to hydrological and geomorphological controls will be explored in the following sections.

\section{Influence of channel morphology on gravel transport: general comments}

It has long been recognized that channel morphology influences particle dispersion in gravel-bed rivers (Takayama, 1965; Laronne and Carson, 1976; Hassan et al., 1991; Sear, 1996; Beechie. 2001; Pyrce and Ashmore, 2003a, b, 2005; Lamarre and Roy, 2008b; Milan, 2013b; Hassan and Bradley, 2017). In RP channels, pools and bars are a major control on gravel path lengths as suggested by Pyrce and Ashmore (2003) who have shown that the mode of the path length distribution coincides with known pool-bar spacing. Bar spacing may also influence particle travel distances in braided rivers (Habersack, 2001; Hundey and Ashmore, 2009; Kasprak et al., 2015). SP channels do not have bars, but it is to be expected that the movement of individual particles may be controlled by the large morphological features such as the steps and the pools (Lamarre and Roy, 2008b). Our results point at the same direction: strength of correlation linking travel distance to stream power increases when tracer travel distances are normalized by the morphological length of channel.

Channel morphology does not only influence particle pathways, but the latter also contributes to the maintenance of bedforms (Sear, 1996; Milan et al., 2002; Lamarre and Roy, 2008a; Milan, 2013b). Our results highlight some differences in between SP and RP channels in the way moving gravels interact with macroforms. During more frequent floods, gravels in RP channels only tend to travel from one morphological unit to the next, while in SP streams tracers are conveyed more easily across several channel units. In addition, sediment travel distances in PB and narrow RP channels are considerably lower when compared to both wide RP and PB 
channels (Figure 2B). The observed differences amongst morphological styles described here may relate to cross-stream differences in channel topography (and bed shear stresses) and as such disparities in lateral dispersion and sediment trapping between the different settings.

\section{Gravel transport in plane-bed channels}

PB morphologies in gravel-bed channels are featured by smooth beds and relatively simple trapezoidal cross-sections. Friction losses due to form effects are then less important in $\mathrm{PB}$ channels compared to RP and SP, where hydraulics is complicated by a more heterogeneous cross-sectional morphology (Francalanci et al., 2012). In this sense, PB streams have been considered similar to the flume (Recking et al., 2016). In figure 4 we showed that tracer travel distances for PB tend to plot in the lower envelope of the compiled data.

Bed structuration and particle arrangements may play a role in the lower tracer transport reported here for PB channels. In flat gravel-bed surfaces there have been described a set of surface structures as clusters, 'stone cells', stone lines or transverse ribs (Church et al., 1998) that are frequent in natural gravel-, plane-bed rivers (Church and Zimmerman, 2007; Venditti et al., 2017). These structures may be a major-stability promoting mechanism in plane-bed channels (Church et al., 1998), increasing the needs for energy in order to displace tracers. Indeed, unconstrained PB data tend to plot over constrained PB data (Figure 4) pointing out at the role of surface structuration on gravel transport in PB channels.

Additionally, in PB channels there are no remarkable topographical constraints imposing a preferential gravel pathway. As such, sediments may be diffused not only downstream but they may also be diverted laterally (Seizilles et al., 2014), decreasing the relative importance of the downstream component of tracer transport. 
Field observations by Papangelakis and Hassan (2016) in East Creek (Canada) pointed in the same direction; after comparing tracer mobility maps for a RP- and a PB-reach ('rapid' morphology, in the sense of Zimmerman and Church, 2001), they observed how the mobility of tracers is more evenly spread across the bed in the PB reach, lacking on preferential paths for tracer mobility.

\section{Gravel transport in step-pool channels}

SP channels are defined by channel-spanning ribs (steps) composed by an accumulation of jammed cobbles and boulders that are transverse or oblique to the channel (Zimmerman and Church, 2001; Chin and Wohl, 2005), alternating with pools containing finer bed material (Church and Zimmerman, 2007; Lamarre and Roy, 2008b). The SP morphology plays an important role in channel hydraulics, controlling hydraulic resistance (Wohl and Grodek, 1994; Abrahams et al., 1995), energy dissipation (Hayward, 1980; Whittaker and Jaeggi, 1982) and defining a highly turbulent tumbling hydraulic regime (Peterson and Mohanty, 1960; Whittaker, 1987). Boulders are responsible of important form resistance as they give rise to leeside eddies (Wohl and Thompson, 2000; Church and Zimmermann, 2007), and at high flows energy is also dissipated by recirculating cells in the pools (Church and Zimmermann, 2007). These particular morphological and hydraulic featuring of steppool channels should play a significant role on the distance of displacement of the bed material (Dudley, 2007; Lamarre and Roy, 2008b). Boulders and steps along the longitudinal profile of SP systems may act as a barrier to mobile particles (Sawada et al., 1983). They may entrap particles and delay entrainment, and therefore influence travel distances. Pools may also act as sedimentation areas in SP channels (Schmidt and Ergenzinger, 1992). The average step-pool length may thus control the average travel distance of tagged clasts, as reported by Lamarre and Roy (2008b) in 
Spruce Creek. However, secondary modes in travel distance distributions of tracers have been documented in most SP channels, indicating that particles traverse several step-pool units during a flow event (Hassan and Bradley, 2017). Indeed, our analysis also confirms that tracers are able to traverse several step-pool pairs during high flows (Figure 4). Consequently, steps are not totally 'impermeable' barriers. Topographic lows and highs could be identified in the cross-section of steps (Dudley, 2007; Church and Zimmermann, 2007), and the topographic lows may act as 'escaping' pathways for tracers during floods as observed by Dudley (2007). Furthermore, a combination of high turbulence and gravity may deflect gravel towards topographic lows during floods, allowing tracers to travel downstream further than a single step-pool unit (Dudley, 2007).

Travelling gravel interacting with the step-pool morphology may contribute to the bedform stability. The hydraulic (e.g. Whittaker and Jaeggi, 1982; Comiti et al., 2005) or geomorphic (e.g. Church and Zimmermann, 2007; Curran, 2007) character of the processes leading to step formation and maintenance are still debated, but it is agreed that large boulders may act as anchor points to initiate step formation (Chin and Whol, 2005; Church and Zimmerman, 2007; Lamarre and Roy, 2008a). According to Church and Zimmerman (2007), grains form interlocked chains across SP channels and thus interact to increase their threshold of motion ('jammed' state hypothesis). Lamarre and Roy (2008a) showed how the development and maintenance of sediment structures in a SP channel were mostly related to the entrapment and settlement of particles around keystones. This may explain while for frequent floods (Figure 5), tracer travel distances are around one to only a few steppool units. Tagged particles may deposit mostly around keystones, becoming imbricated into sediment structures, increasing threshold stresses and remaining 
stored for several transport events (Lamarre and Roy, 2008a). However, large floods can cause the break up and rearranging of the SP structure (Church and Zimmerman, 2007; Zimmerman et al., 2010). Field researchers have documented high bedload rates after large floods in SP channels (Gintz et al., 1996; Lenzi et al., 1999; Lenzi et al., 2004; Turowski et al., 2009) and this has been attributed to the decrease of form roughness of the channel bed and the fact that larger grains become more mobile after SP destabilization. This may explain our observation suggesting that tracers can travel farther than a few SP pairs during larger floods (Figure 4 and 5).

Moreover, mean tracer travel distances are considerably lower in constrained compared to unconstrained experiments in SP channels. Hence, SP channels appear to be steep enough to maintain significant transport of 'free' sediment, while lacking sufficient energy to disturb the coarser armoured bed sediment. This could have implications from the point of view of bed load supply: SP channels are able to have sufficient capacities to transport allogenic sources of relatively fine sediment through the channel while the streambed remains stable (Piton and Recking, 2017). Field researchers have already shown that sediment transport rates in SP are dependent on sediment supply (e.g. Gintz et al., 1996; Lenzi et al., 1999, 2004; Recking et al., 2012; Kammerlander et al., 2017). Indeed, the prediction of bedload transport in SP streams has revealed as being very difficult due to its dependence on the availability of mobile sediment and related to the fact that many sediment transport equations do not account for the stress borne by immobile grains (Yager et al., 2012a, b). In this sense, working in steep SP systems, previous authors have made a distinction between travelling bed load and structured bed load (e.g., Yu et al., 2009). The structured bed load may define the scale of roughness elements in 
SP channels and influence flow resistance, while the travelling bed load may relate to the supply-limited and more mobile sediment introduced sporadically into the channel. Very recently, Piton et al. (2016) and Piton and Recking (2017) built on this concept of travelling bed load, which they explicitly state as an extension of the washing load concept to bed load transport. According to these authors, in steep SP systems, relatively fine sediment supplied by external sources may be efficiently transported during floods, with marginal morphological activity and without the breaking up of coarse armoured surfaces (Egashira and Ahida, 1991; Piton and Recking, 2017). The different behaviour of constrained and unconstrained tracer experiments in SP data reported in this study points in the same direction.

\section{Gravel transport in riffle and pool channels}

RP channels are featured by an alternation of areas of shallow (riffle) to deeper waters (pool) in a more or less regular pattern. Unlike SP and PB channels, bars are present in RP channels (Dietrich, 1987), and early studies already outlined the influence of the bar morphology on gravel dispersion (Mosley, 1978; Kondolf and Mathews, 1986). Later, Pyrce and Ashmore (2003a) reanalysed data from a wide range of river environments and found that distributions of travel distances in gravelbed streams include modes corresponding to bars. Flume experiments by Pyrce and Ashmore $(2003 \mathrm{~b}, 2005)$ also showed the role that bars have on tracer travel distances. Somehow, RP channels have a more developed cross-sectional morphology than PB and SP channels. This cross-sectional morphology results from the existing feedbacks between the very specific patterns of flow conveyance and sediment routing in RP morphologies (Dietrich and Smith, 1983; Smith and McLean, 1984; Dietrich and Whiting, 1989), and the topography-driven sorting processes induced by bars (Dietrich et al., 1983, 1984; Paola, 1989; Nelson et al., 2010). This 
results in a high heterogeneity in elevation, roughness and surface grain size (Petit, 1987; Carling, 1991; Lisle et al., 1991; Robert, 1997; Wilkinson et al., 2008; Venditti et al., 2012) that may involve a great variability in shear stress distribution in RP channels (Whiting and Dietrich, 1991) and spatial contrasts in entrainment conditions between pools and riffles (Clifford, 1993; Sear, 1996). In a recent reanalysis of bedload measures in different bed morphologies, Recking et al. (2016) observed that larger corrections are needed in RP channels compared to SP and PB channels for compensating the bias introduced by averaging shear stresses when computing bedload transport (Francalanci et al., 2012).

All the variability in roughness, shear stresses and reach-scale topography in RP morphologies influences bedload by concentrating the flow and the sediment in preferential paths. Coarser sediments are preferentially transported onto bar heads due to inertia effects. This zone grows and leads to secondary flows diverting the flow and finer sediments to the opposite side (see Figure 15 in Recking et al., 2016), an effect that is also increased by differences in roughness (Lisle et al., 1991; Nelson et al., 2010; Recking et al., 2016). Hence, variability in bed mobility across the RP sequence (Clifford, 1993; Sear, 1996; Hodge et al., 2013) is responsible for intrinsic differences in sediment transport between riffle and pool, and shear stress gradients across and along RP channels determine scour in pools and deposition in riffles (Wilkinson et al., 2004). Early painted stone experiments by Ashworth (1987) in Allt Dubhaig showed that tracers seeded in riffles had lower entrainment probability and lower mean travel distance than those seeded in pools. Conversely, Haschenburger and Church (1998) did not observe differences in tracer deposition according to tracer source. Haschenburger and Church (1998) also observed significant tracer deposition in pool areas. However, detailed observations made later by Milan (2002) 
and Milan (2013b) showed how gravels tend to be routed out from pools and how the dominant depositional zones of tracer clasts in RP channels are the bars followed by the riffles (Milan, 2013b). Milan (2013b) explained tracers occasionally found on pools as particles having been routed across bar surfaces and then rolled down the avalanche face into the pool (as in Dietrich and Smith, 1984).

Size selective deposition and particle paths have been described for RP channels. Sear (1996) observed how coarse gravels are normally stored in riffles and poolheads whilst fine gravels are mainly stocked in mid-pool and pool-tails. He also reported that fine sediment travels across riffle-pool-riffle sequence and concentrates in the downstream riffle. Additionally, Milan et al. (2002) and Milan (2013b) observed grain size differences with flow magnitude. At low flows, fine sediment is routed onto riffles and pool-heads. Transport of gravel starts at moderate flows, being routed downstream from bar heads through bar-edges. At high flows, both fine and coarse sediment are transported onto the bar surface, depositing there in the falling limb of flow hydrograph. In those RP streams with high supply of fines, fine sediment deposited on riffles during high flows may be selectively winnowed onto the pools during the falling limbs of flow hydrographs (Lisle and Hilton, 1992).

In summary, the flow trajectories resulting from the RP cross-sectional variability influence the patterns of particle displacement and gravel routing in RP sequences. Gravel paths tend to follow streamlines contributing to maintain the RP morphology (Milan, 2013b). An important number of particles may be conveyed towards barheads and -tops during floods in RP channels (Milan, 2013b), i.e. stable positions reducing their potential for downstream transport. Bars seem to be a preferential storage site in RP channels, followed by riffles (Milan et al., 2002; Milan, 2013b). Furthermore, Wathen (1995) and Bradley and Tucker (2012) reported that in RP 
channels a large number of tracers remained trapped in bars, even after several competent flow events. The result is a high efficiency of RP morphology for trapping sediment compared to SP or PB channels, as figure 4 showed: i. for similar hydraulic inputs, tracers travel across more morphological units in SP than in RP, on average; and ii. mean travel distances, normalized by the morphological length of channel, scaled with stream power in RP channels with a gentler slope than they do in SP and PB channels (Figure 4). Bar morphology in RP channels is a very persistent feature, and it may continue to influence bedload paths and trapping gravels even during high flows (Milan, 2013b). This may explain the gentle scaling of travel distance with stream power in RP channels compared to SP, where step-pool destabilization during large floods may allow larger tracer dispersal.

\section{Gravel transport in multithread channels}

Even though we have reached a good scientific understanding of the mechanisms driving braiding morphodynamics (e.g. Ashmore, 1991; Ashmore, 2013), there is still a real gap in the availability of actual field data linking particle travel lengths and channel morphology in braided streams (Church, 2006; Kasprak et al., 2015). There are no many systematic observations of tracer displacement coming from multithread and/or braided rivers (Kasprak et al., 2015). Amongst the wide data set compiled for this work, only the upper reaches of the Alt-Dubhaig (Ashworth, 1987; Ferguson and Wathen, 1998), the Durance (Chapuis et al., 2012) and Bouinenc rivers (Liébault et al., 2012) correspond to wandering/braided rivers. And unfortunately, the recovery ratios for two of these sites (upper reaches of the AltDubhaig river and the Durance river) are not high $(<75 \%)$. Due to this relative scarcity of systematic tracer studies in multithread or braided environments, understanding the grain-scale bedload transport processes and their relationship to 
channel morphology in the field remains insufficient in braiding settings (Kasprak et al., 2015; Bertoldi et al., 2014; Recking et al., 2016).

Early field and flume studies by Ashworth et al. (1992a, b) and Ashworth (1996) on bar formation in braided rivers showed how flow divergences at emergent bar heads lead to the concentration of relatively coarse material and the routing of fine sediments into distributary channels. More recently, Hundely and Ashmore (2009) has hypothesised that bar spacing quantified by the distance between confluence/diffluence couplets may provide a first-order approach to gravel travel distances in braided channels. Habersack (2001) used particle radio tracking in the Waimakiri braided river (New Zealand) and provided early evidence for this, documenting the preferential deposition of tracked particles on an aggrading bar. More recently, Kasprak et al. (2015) used high-resolution elevation models derived from SfM photogrammetry in the flume in order to study the downstream transport of tagged particles in braided channels. They reported average sediment path lengths corresponding roughly to the average bar spacing. This study confirmed the influence of bars in acting as preferential depositional sites for tagged particles in braided rivers, with almost all retrieved tracers found in association with compound, lateral, diagonal and point bars. They documented that about $70 \%$ of tracers where found in bar heads and margins, a smaller amount in bar-tops and only $3 \%$ in bartails. These observations agreed well with Ashworth's model of bar formation in braided rivers (Ashworth et al., 1992b; Ashworth, 1996) that involves coarse sediment deposition around bar heads and conveyance of more mobile sediment mainly through bar margins and distributary channels. Liébault et al. (2012) also found that bars were major storing zones in the wandering/braided Bouinanc river. These patterns of particle paths may promote a positive feedback reinforcing the 
location and persistence of gravel bars (Ashworth, 1996; Hundey and Ashmore, 2009; Kasprak et al., 2015).

Kasprak et al. (2015) did not found any influence of seed location in the downstream deposition sites of tracers. However, Liébault et al. (2012) documented a clear influence of tracer source in particle travel distances in the wandering/braided Bouinenc river: they observed a 15- to 30 -fold increase of dispersion for tracers initially seeded in the low-flow channel as compared to those initially located in gravel-bars. Based on their observations, they suggested that tracers initially seeded in the thalweg were not trapped by gravel bars and travelled far along the main channel. Methodological biases could explain differences between the flume results of Kasprak et al (2015) and the field observations of Liébault et al. (2012): buried tracers were not recovered in the flume study of Kasprak et al. (2015). In this sense,

Liébault et al. (2012) have shown that tracer travel distances of buried tracers are significantly larger - that is, the probability of tracer to be buried increases with its travel distance. According to this, frontrunners may not be adequately grasped in Kasprak's study. In addition, tracer recovery ratios were in general lower in Kasprak et al. (2015) than in Liébault et al (2012).

\section{Influences of grain size}

Results from tracer studies helped establish that the mean travel distance of fluvial gravels during competent floods is weakly correlated to the increasing particle size (Church and Hassan, 1992; Hassan and Church, 1992; Ferguson and Wathen, 1998; Schneider et al., 2014). Church and Hassan (1992) and Hassan and Church (1992) related the mean travel distance of fluvial gravels to the particle size relative to the median size of the bed material: particle size plays an important role in the downstream transport distance of tracers only at the coarser members of the bed 
grain size distribution $\left(>2 D_{50}\right)$, whereas for intermediate grain sizes transport distances are mostly independent of clast diameter. Wilcock (1997) confirmed this relation in a flume, and several authors found similar trends with field data (e.g. Ferguson and Wathen (1998), Haschenburger (1996), Ferguson et al. (2002), Vázquez-Tarrío and Menéndez-Duarte, 2014). Based on our data set compilation, in figure 7 we have added new points to the plot originally presented by Church and Hassan (1992), Hassan and Church (1992) and Hassan and Bradley (2017): the new data introduce some amount of scatter, but in general the relation continues to hold. In addition, the relation seems to be pretty independent on the morphological style of channel.

In summary, particle size relative to bed sediment influences gravel transport distances that decrease with increasing clast size. According to Phillips and Jerolmack (2014) this decrease in travel distances with grain size is mostly controlled by competent flow duration. They observed how modal displacement lengths for particles of all sizes in a gravel bed river were very similar at the individual flood scale. Conversely, Phillips and Jerolmack (2014) observed that cumulative travel distances showed a stronger inverse relation to grain size when measured over many transport events. Then, the relative larger displacements for smaller particles showed in figure 7 may result from a greater frequency of entrainment events during a flood for smaller particles compared to the coarser ones (Phillips and Jerolmack, 2014).

\section{Influences of the duration of competent flow and bed state}

Our results show some increase in the degree of tracer mobility with a rise in the duration of competent flow: both tracer travel distance and percentage of mobile tracers tended to increase with flow duration (Figures 9 and 11B). Differences in 
behaviour exist here again, particularly between unconstrained and constrained conditions in SP channels. In unconstrained conditions, tracers are free to move, so their mobility increased more quickly with the increment in available time. Conversely, in constrained tests, it is the breakup of stable positions of tracers in bed structures and particle arrangement that predominantly determine tracer mobility, a process that is less dependent on flow duration.

A comparison of constrained and unconstrained data brings to light the influence of another control on particle travel distances that is not linked to either flow magnitude or channel morphology: the relationship between bed state and particle entrainment. A more stable coarse bed will act to reduce sediment mobility (constrained case) and increase energy expenditure required to move surface particles, an idea supported by results from Brayshaw et al., (1983), Hassan et al. (1992) and Hassan and Bradley (2017). Hassan and Bradley (2017) compared tracer data for gravel bed streams with tracer data of gravel movement over a sand bed and they found travel distances in the second case to be typically one order of magnitude larger. In the same vein, Klingeman and Emmet (1982) reported that critical shear stresses for incipient motion were greater in the rising limb of a flood due to enhanced bed stability linked to initial armour. Similarly, Turowski et al. (2011) observed in four alpine streams that the discharge at the end of transport in the most recent event is correlated to the threshold discharge for the next event, which they interpret to reflect temporal changes in bed structure. Additionally, Powell and Ashworth (1995) observed how zones of contrasting bed structure may determine important differences on the entrainment thresholds.

Influence of antecedent time and previous bed history 
The inter-flood period has been historically ignored by fluvial geomorphologists as it is typically considered that the stability of the stream bed could only be altered by above threshold flows (Ockelford and Haynes, 2013). However, several studies have pointed at the history of recent flows in the development of bed texture and the potential for influencing sediment dispersion. Olmeadow and Church (2006) reported on a field experiment aimed at studying the development of bed structure in a small headwater stream. In East Creek (British Columbia, Canada) they destroyed bed structures in one reach of the channel while leaving them intact in an adjacent one. Sediment yield from the disturbed reach was initially higher than from the undisturbed one. However, after several events, the mobility of larger clasts was substantially reduced, and they recorded direct evidence of structure development in the disturbed reach indicated by the movement and emplacement of marked grains. A similar experiment was carried out later by Lamarre and Roy using PIT-tags (2008a). Additionally, some of the papers compiled as part of this study report beautiful examples of how preceding flood history influenced tracer dispersion. One such case was reported on by Gintz et al. (1996) for a study using magnetic tracers in the Lainbach river, a step-pool system in Germany. The morphological impacts of a large event resulted in a 10-fold increase in tracer travel distances in the subsequent extreme flood. In the Rio Cordon, Lenzi (2004) described a step-pool channel that was strongly modified after a large flood in 1994. Afterwards, sediment transport declined over several years as the channel re-established a relatively stable bed (Church and Zimmerman, 2007). Earlier studies as well have suggested that sub-threshold flows preceding threshold flows may influence grave mobility. Laronne and Carson (1976) described the influence of bed sediment structures and arrangements on tracer dispersion. Reid and Frostick (1984) and Reid et al. (1985) 
found that threshold stresses were three times higher after a greater period of time before a flood in Turkey Brook (England), and they suggested that this could be related to the effects of bed re-structuration and particle interlocking during the interflood period. More recently, flume experiments have shown that not only threshold floods, but also prolonged interflood periods of sub-threshold flow promote bed stabilization (Monteith and Pender, 2005; Paphitis and Collins, 2005; Haynes and Pender, 2007). Ockelford and Haynes (2013) proposed two potential mechanisms for this: i) vertical settlement of fine particles into low relief pore spaces of the river bed (Frostick et al., 1984; Reid et al., 1985; Marion and Weirich, 2003; Haynes and Pender, 2007); and ii) local re-orientation and restructuring of surface particles (Reid and Frostick, 1984; Haynes and Pender, 2007; Mao, 2012). Very recently, Mao et al. (2017) reported that antecedent flow enhanced particle entrainment of tagged stones in the Saldur river (plane-bed to step-pool morphology).

Tracers constitute an excellent method to evaluate the effects of previous bed history on gravel mobility, but information about the time elapsed between tracer seeding and subsequent competent flows is not typically provided in papers. When available, it is difficult to isolate the role of antecedent time from other variables that exert an important control on tracer dispersion, such as duration or excess stream power. The available data set is not large enough to allow selection of data with similar flow duration/competence but differing elapsed times. Furthermore, the number of days passing between tracer seeding and displacement is not a perfect proxy of a river bed's 'stress history'. It would be more interesting to have access to the actual number of days for which flow exceeded some sub-threshold discharge, or the actual value of specific stream power during the time period preceding tracer movement. 
However, this information is rarely available. Nevertheless, in constrained experiments it seems that tracer mobility decreases with an increase in antecedent time (Figure 10). This suggests that sub-threshold flows might enhance particle packing and imbrication. We believe that more research should be carried out in the near-future aiming at exploring this question and benefitting from the advantages offered by particle-tracking methods.

\section{Practical implications}

The results of this paper may potentially have interesting implications for future research based on tracer data. When reporting the results of tracer experiments, researchers are encouraged to take more care to report on information that has been typically neglected, e.g., cumulative flow, duration of competent flow, description of bed structures, elapsed time between tracer seeding and subsequent surveys. Improvements have been made during the last years, and much more information can be found in recent papers compared to the older ones (see Table 1), but we should remain vigilant. We strongly believe that tracers have a great potential to bolster our understanding of sediment transport providing that complete and homogeneous information is made available from the studies.

In addition, our review of previously published tracer experiences highlights that a large amount of research has been accomplished in single-thread channels, but we are still lacking of more data collected from multithread or braided channels. Braided rivers are featured by a very dynamic channel planform and a frequent downstream mobilization of bed load through a complex network of anabranches diverging and converging around gravel bars. This combination of factors makes braided rivers an ideal site to explore in the field on the relations between particles paths and channel morphology. However, few tracer studies have been performed in the field on 
multithread rivers (Chapuis et al., 2012; Liébault et al., 2012), probably due to the big effort and time needed for surveying after floods in such large rivers. However, new solutions for tracking gravels based on active RFID technology that seem very promising for large rivers are being developed (Cassel et al., 2017). More data from braided settings may be expected in the near future.

Finally, the results of this study may have implications for the design of tracer experiments and subsequent data analysis. With regards to constrained vs unconstrained conditions, special care should be taken when comparing between results from different experiments. As we have shown here, constrained and unconstrained experiments are not necessarily equivalent. If the goal is to study particle entrainment and bed state evolution, the focus should be on results under constrained conditions. However, if the goal is to study trajectories of coarse sediment within a given setting (for example tributary junctions or step to pool), then results from unconstrained cases should be used.

\section{CONCLUSIONS}

In this paper, we compiled and analysed published data on sediment transport in gravel-bed rivers obtained in studies based on passive tracers. Our results highlight three major controls on downstream sediment transport in gravel-bed rivers: i) hydrological/hydraulic controls linked to discharge magnitude, the duration of competent flows, and antecedent sub-threshold flows; ii) morphological controls associated with the average spacing between sediment storing areas; and iii) controls exerted by bed structures and particle arrangements on threshold stresses.

As expected, we found significant correlation between flow magnitude (quantified using the stream power concept) and tracer travel distance, but with a non-negligible amount of scatter. We attribute differences in the length-scale of particle travel 
distances based on channel style to morphological controls and sediment 'trapping'. Concerning the positive impact of flow duration on the percentage of mobilised tracers, we attribute this to an increase in the duration of bed perturbation. Finally, although the data in this study are insufficient to draw decisive conclusions, they suggest that antecedent subthreshold flows influence bed state thereby conditioning particle dispersion.

Acknowledgements. The present work has been possible thanks to the financial support provided by the grants ACA14-30 and ACB17-44, cofunded by the postdoctoral 'Clarin' program-FICYT (Government of the Principality of Asturias) and the Marie Curie Cofund. We would like to acknowledge managing editor Stuart Lane, associate editor Fiona Kirkby, and the two anonymous reviewers for their comments that helped to improve the final version of the paper. 


\section{REFERENCES}

Abrahams AD, Li G and Atkinson JF. 1995. Step-Pool Streams: Adjustment to Maximum Flow Resistance. Water Res. Res., Vol. 31, No. 10, pp. 2593-2602.

Ashmore, P.E. 1991. How do gravel-bed rivers braid? Canadian Journal of Earth Sciences, 28 (3), 326-341.

Ashmore, P. E. 2013. Morphology and dynamics of braided rivers. In: Shroder I (ed) Treatise on geomorphology, vol 9. Academic Press, Waltham, pp 289-312 .

Ashworth PJ. 1987. Bedload transport and channel change in gravel-bed rivers, Ph.D thesis, Univ. of Stirling, Scotland, 1987, 352 pp.

Ashworth PJ, Ferguson RI, Ashmore PE, Paola C, Powell DM and Prestegaard KL. 1992a. Measurements in a braided river chute and lobe. 2. Sorting of bedload during entrainment, transport and deposition. Water Resources Research, 28, 1887-96.

Ashworth PJ, Ferguson RI and Powell DM 1992b. Bedload transport and sorting in braided channels. In Billi, P., Hey, R.D., Thorne, CR and Tacconi P, (eds.). Dynamics of gravel-bed rivers. Chichester, Wiley, 497-513.

Ashworth PJ. 1996. Mid-channel bar growth and its relationship to local flow strength and direction. Earth Surface Processes and Landforms, 21, 103-23.

Bagnold RA. 1966. An approach to the sediment transport problem from general physics. United States Geological Survey Professional Paper 422I.

Bagnold RA. 1980. An empirical correlation of bedload transport rates in flumes and natural rivers. Royal Society of London Proceedings, A372, 453-473.

Beechie TJ. 2001. Empirical predictors of annual bed load travel distance, and implications for salmonid habitat restoration and protection. Earth Surface Processes Landforms, 26(9), 1025-1034. 
Bertoldi W, Recking A. and Surian N. 2014. Braiding Rivers: State of the Art and Future Challenges, Eos, Transactions American Geophysical Union, 95 (42), 381.

Bradley DN and Tucker GE. 2012. Measuring gravel transport and dispersion in a mountain river using passive radio tracers. Earth Surface Processes and Landforms, $37,1034-1045$.

Brayshaw AC, Frostick LE and Reid I. 1983. The hydrodynamics of particle clusters and sediment entrainment in coarse alluvial channels. Sedimentology, 30, 137-143.

Butler RP. 1977. Movement of cobbles in a gravel bed stream during a flood season. Geological Society of America Bulletin 88: 1072-1074.

Camenen B, Le Coz J, Pacquier P and Lagouy M. 2010. An estimation of gravel mobility over an alpine river gravel bar (Arc en Maurienne, France) using PIT-tag tracers. 5th International Conference on Fluvial Hydraulics (River Flow 2010), Braunschweig, Germany, 8-10 September 2010.

Carling PA. 1991. An appraisal of the velocity-reversal hypothesis for stable poolriffle sequences in the River Severn, England. Earth Surface Processes and Landforms, 16, 19-31.

Carré DM, Biron PM and Gaskin SJ. 2007. Flow dynamics and bedload sediment transport around paired deflectors for fish habitat enhancement: A field study in the Nicolet River. Can. J. Civ. Eng., 34, 761-769.

Cassel M, Dépret T and Piegay H. 2017. Assessment of a New Solution for Tracking Pebbles in Rivers Based on Active RFID. Earth Surface Processes and Landforms, doi: 10.1002/esp.4152.

Chapuis M. 2012. Bed Mobility in Highly Modified Fluvial Systems: Keys for Understanding River Management (Durance River, South-Eastern France). Ph.D. Dissertation (in French). Université Aix-Marseille 1, Aix-en-Provence, France. 
Chin A and Wohl E. 2005. Toward a theory for step pool in stream channels. Progresses in Physical Geography, 29, 275 - 296.

Church M. 2006. Bed material transport and the morphology of alluvial river channels. Annu. Rev. Earth Planet. Sci., 34, 325-354.

Church M and Hassan MA. 1992. Size and distance of travel of unconstrained clasts on a streambed. Water Resources Research, 28, 299-303.

Church M, Hassan MA and Wolcott JF. 1998. Stabilizing self-organized structures in gravel-bed stream channels: Field and experimental observations. Water Resources Research, 34, 3169-3179.

Church M and Zimmermann A. 2007. Form and stability of step-pool channels: Research progress. Water Resources Research. 43: W03415.

Clifford NJ. 1993. Differential bed sedimentology and the maintenance of riffle-pool sequences. Catena, 20 (5), 447-468.

Comiti F, Andreoli A and Lenzi MA. 2005. Morphological effects of local scouring in step-pool streams. Earth Surface Processes and Landforms, 30, 1567 - 1581.

Curran JC. 2007. Step-pool formation models and associated step-spacing. Earth Surface Processes and Landforms, 32 (11), 1611-1627.

Dell'Agnese A, Brardinoni F, Toro, M., Mao L, Engel M, and Comiti F. 2015. Bedload transport in a formerly glaciated mountain catchment constrained by particle tracking. Earth Surface Dynamics, 3, 527-542.

Dietrich WE. 1987. Mechanics of flow and sediment transport in river bends. In : Richards K., (ed.). River Channels: Environment and Process, Basil Blackwell, Oxford, pp. $179-227$.

Dietrich WE. and Smith JD. 1983. Influence of the point bar on flow through curved channels. Water Resources Research, 19 (5), 1173-1192. 
Dietrich WE and Smith JD. 1984. Bed load transport in a river meander. Water Resources Research, 20 (10), 1355-1380.

Dietrich WE and Whiting P. 1989. Boundary shear stress and sediment transport in river meanders of sand and gravel. In : Ikeda $\mathrm{H}$ and Parker $\mathrm{G}$ (eds.). River meandering. Water Resources Monograph 12, American Geophysical Union, Washington DC, pp. 1-50.

Diplas P, Chatanantavet P and Almedej J. 2016. Streambed structure, stream power and bed load transport: a unified outlook for gravel-bed and bedrock streams. In: Contastinescu G, García M and Hanes D. (eds.). River Flow 2016, Taylo and Francis Group, Lonfon, 987-994.

Dudley J. 2007. Channel form, flow and sediment transport in a step-pool stream. PhD dissertation, Loughborough University.

Eaton B and Church M. 2011. A rational sediment transport scaling relation based on dimensionless stream power. Earth Surface Processes and Landforms, 36 (7), 901910.

Egashira S and Ashida K. 1991. Flow resistance and sediment transportation in streams with step-pool bed morphology. In : Armanini A. and Di Silvio G. (eds.). Fluvial Hydraulics of Mountain Regions, Lect. Notes Earth Sci., vol. 37, Springer, New York, pp. $45-58$.

Ergenzinger $\mathrm{P}$ and Schmidt KH. 1995. Single particle bed load transport: first results from new approaches. Z Geomorphol. Suppl. Bd. 100, 193-203.

Ferguson R and Hoey T. 2002. Long-term slowdown of river tracer pebbles: Generic models and implications for interpreting short-term tracer studies. Water Resources Research, 38, 1142. 
Ferguson R and Wathen S. 1998. Tracer-pebble movement along a concave river profile: Virtual velocity in relation to grain size and shear stress. Water Resources Research, 34, 2031-2038.

Ferguson R, Bloomer D, Hoey T. and Werritty A. 2002. Mobility of river tracer pebbles over different timescales. Water Resources Research, 38, 1045.

Francalanci S, Solari L, Toffolon M and Parker G. 2012. Do alternate bars affect sediment transport and flow resistance in gravel-bed rivers? Earth Surface Processes and Landforms, 37 (8), 866-875.

Gintz D, Hassan MA and Schmidt KH. 1996. Frequency and magnitude of bedload transport in a mountain river. Earth Surface Processes and Landforms, 21, 433-445. Habersack HM. 2001. Radio-tracking gravel particles in a large braided river in New Zealand: a field test of the stochastic theory of bed load transport proposed by Einstein, J. Hydrol. Processes, 15, 3, 377-391.

Haschenburger JK. 1996. Scour and fill in a gravel-bed channel: Observations and stochastic models, Ph.D. thesis, Univ. of B. C., Vancouver, Canada,144 pp.

Haschenburger JK. 1999. A Probability model of scour and fill depths in gravel-bed channels. Water Resources Research, 35, 2857-2869.

Haschenburger JK. 2011. The rate of fluvial gravel dispersion. Geophysical Research Letters, 38.

Haschenburger JK. 2013. Tracing river gravels: Insights into dispersion from a longterm field experiment. Geomorphology, 200, 121-131.

Haschenburger JK and Church M. 1998. Bed material transport estimated from the virtual velocity of sediment, Earth Surf. Processes Landforms, 23, $791-808$.

Haschenburger JK and Wilcock PR. 2003. Partial transport in a natural gravel bed channel. Water Resources Research 39. 
Hassan MA. 1990. Scour, fill, and burial depth of coarse material in gravel bed streams. Earth Surface Processes and Landforms, 15, 341-356.

Hassan M and Bradley DN. 2017. Geomorphic controls on tracer particle dispersion in gravel bed rivers. In: Tsutsumi D and Laronne JB. (eds.). Gravel-bed rivers. Processes and disasters, Wiley-Blackwell, UK, PP. 439-466.

Hassan MA and Church M. 1992. The movement of individual grains on the streambed. In Bill P Hey CR, Thorne CR and Tacconi P. (Eds.). Dynamics of Gravel bed Rivers. Chichester, John Wiley \& Sons.

Hassan MA and Church M. 1994. Vertical mixing of coarse particles in gravel bed rivers: a kinematic model. Water Resources Research, 30, 1173-1186.

Hassan MA, Church M and Ashworth PJ. 1992. Virtual rate and mean distance of travel of individual clasts in gravel-bed channels. Earth Surface Processes and Landforms, 17, 617-627.

Hassan MA, Church M and Schick AP. 1991. Distance of movement of coarse particles in gravel bed streams. Water Resources Research, 27, 503-511.

Hassan MA and Ergenzinger P. 2003. Use of Tracers in Fluvial Geomorphology. Tools in fluvial geomorphology. John Wiley \& Sons, Ltd.

Hassan MA and Roy A. 2015. Use of Tracers in Fluvial Geomorphology. Tools in Fluvial Geomorphology. 2nd ed., John Wiley \& Sons, Ltd.

Hassan M, Schick A and Laronne J. 1984. The recovery of flood-dispersed coarse sediment particles. Catena Suppl. 5, 153-162.

Haynes H and Pende, G. 2007. Stress history effects on graded bed stability. J. of Hydraul. Eng., 133, 4, 343-349. 
Hayward JA. 1980. Hydrology and stream sediment from Torlesse stream catchment, Spec. Publ. 17, Tussock Grasslands and Mountain Lands Inst., Lincoln Coll., Lincoln, III, 236 pp.

Hodge RA, Sear DA and Leyland J. 2013. Spatial variations in surface sediment structure in riffle-pool sequences: a preliminary test of the Differential Sediment Entrainment Hypothesis (DSEH). Earth Surface Processes and Landforms, 38 (5),

\section{$449-465$.}

Houbrechts G, Levecq Y, Vanderheyden V and Petit F. 2011. Long-term bedload mobility in gravel-bed rivers using iron slag as a tracer. Geomorphology, 126 (1-2), 233-244

Houbrechts G, Levecq Y, Peeters A, Hallot E, Campenhout JV, Denis AC and Petit F. 2015. Evaluation of long-term bedload virtual velocity in gravel-bed rivers (Ardenne, Belgium). Geomorphology, 251 (15), 6-19.

Hundey EJ and Ashmore PJ. 2009. Length scale of braided river morphology. Water Resources Research, 45.

Kammerlander J, Gems B, Köbler D and Aufleger M. 2017. Effect of bed load supply on sediment transport in mountain streams. International Journal of Sedimentary Research, 32 (2), 240-252.

Kasprak A, Wheaton JM, Ahmore PE, Hensleigh JW and Peirce S. 2015. The relationship between particle travel distance and channel morphology: Results from physical models of braided rivers. Journal of Geophysical Research. Earth Surface, 120.

Keller EA. 1970. Bed-load Movement Experiments: Dry Creek, California. Journal of Sedimentary Petrology 40, 1339-1344. 
Klingeman PC and Emmett WW. 1982. Gravel bedload transport processes. In Hey RD, Bathurst JC and Thorne CR. (eds.). Gravel bed rivers: fluvial processes, engineering and management, Chichester, Wiley, pp. 141-69.

Klösch M and Habersack H. 2018. Deriving formulas for an unsteady virtual velocity of bedload tracers. Earth Surface Processes and Landforms.

Kondolf GM and Mathews WVG. 1986. Transport of tracer gravels on a coastal California river. Journal of Hydrology, 85 (3-4), 265-280.

Lamarre H, MacVicar B and Roy A. 2005. Using passive integrated transponder (PIT) tags to investigate sediment transport in gravel-bed rivers. Journal of Sedimentary Research, 75, 736-741.

Lamarre H and Roy AG. 2008a. A field experiment on the development of sedimentary structures in a gravel-bed river. Earth Surface Processes and Landforms, 33, 1064-1081.

Lamarre H and Roy AG. 2008b. The role of morphology on the displacement of particles in a step-pool river system. Geomorphology, 99, 270-279.

Laronne $\mathrm{J}$ and Carson M. 1976. Interrelationships between bed morphology and bed material transport for a small, gravel-bed channel. Sedimentology, 23, 67-85.

Lenzi MA. 2004. Displacement and transport of marked pebbles, cobbles and boulders during floods in a steep mountain stream. Hydrological Processes, 18, 1899-1914.

Lenzi MA, D'Agostino V and Billi P. 1999. Bedload transport in the instrumented catchment of the Rio Cordon, part I: Analysis of bedload records, conditions and threshold of bedload entrainment. Catena, 36, 171-190.

Lenzi M, Mao L and Comiti F. 2004. Magnitude-frequency analysis of bed load data in an Alpine boulder bed stream. Water Resources Research, 40. 
Leopold LB and Emmett WW. 1981. Some observations on the movement of cobbles on a streambed. In: Proceedings of the International Symposium on the Measurement of Erosion and Sediment Transport, Florence, Italy, June 22-25, 1981. Publication no. 133, v. 2, International Association of Hydrological Sciences. p. 4960

Liébault $F$ and Laronne JB. 2008. Factors affecting the evaluation of bedload transport in gravel-bed rivers using scour chains and painted tracers: the case of the Esconavette Torrent, Geodinamica Acta, 21, 23-34.

Liébault $\mathrm{F}$, Bellot $\mathrm{H}$, Chapuis $\mathrm{M}$, Klotz $\mathrm{S}$ and Deschàtres M. 2012. Bedload tracing in a high-sediment-load mountain stream. Earth Surface Processes and Landforms, 37, 385-399.

Lisle TE and Hilton T. 1992. The volume of fine sediment in pools: an index of sediment supply in gravel-bed streams. Water Resources Bulletin, 28 (2), 371-383.

Lisle TE, Ikeda $\mathrm{H}$ and Iseya F. 1991. Formation of a stationary alternate bars in a steep channel with mixed-size sediment: a flume experiment. Earth Surface Processes and Landforms, 16, 463-469

MacVicar B, Chapui M., Buckrell E. and Roy A. 2015. Assessing the Performance of In-Stream Restoration Projects Using Radio Frequency Identification (RFID) Transponders. Water, 7, 5566-5591.

MacVicar B and Roy A. 2011. Sediment mobility in a forced riffle-pool. Geomorphology,125, 445-456.

Mao L. 2012. The effect of hydrographs on bed load transport and bed sediment spatial arrangement. Journal of Geophysical Research. Earth Surface, 117.

Mao L, Dell'Agnese A and Surian N. 2017. Sediment motion and velocity in a glaciarfed stream. Geomorphology, 291, 69-79. 
Mao L, Picco L, Lenzi MA and Surian N. 2016. Bed material transport estimate in large gravel-bed rivers using the virtual velocity approach. Earth Surface Processes and Landforms, 4 (2), 595-611.

Marion DA and Weirich F. 2003. Equal-mobility bed load transport in a small, steppool channel in the Ouachita Mountains. Geomorphology, 55, 139 -154.

McNamara JP and Borden C. 2004. Observations on the movement of coarse gravel using implanted motion-sensing radio transmitters. Hydrological Processes, 18, $1871-1884$.

Milan DJ, Heritage GL and Large, ARG. 2002. Tracer pebble entrainment and deposition loci: influence of flow character and implications for riffle-pool maintenance. In Jones SJ and Frostick LE. (eds). Sediment Flux to Basins: Causes, Controls and Consequences. Geological Society of London Special Publications 191. The Geological Society: London; 133-148.

Milan DJ. 2013a. Virtual velocity of tracers in a gravel-bed river using size-based 829 competence duration. Geomorphology, 198, 107-114.

Milan DJ. 2013b. Sediment routing hypothesis for pool-riffle maintenance. Earth Surface Processes and Landforms, 38 (14), 1623-1641.

Monteith $\mathrm{H}$ and Pender G. 2005. Flume investigations into the influence of shear stress history on a graded sediment bed. Water Resources Research, 41, W12401, Montgomery DR and Buffington JM. 1997. Channel-reach morphology in mountain drainage basins. Geological Society of America Bulletin, 109, 596-611.

Mosley MP. 1976. An experimental study of channel confluences. Journal of Geology, 84, 535-562. 
Nelson PA, Dietrich WE and Venditti JG. 2010. Bed topography and the development of forced surface patches. Journal of Geophysical Research. Earth Surface, 115.

Nichols M. 2004. A radio frequency identification system for monitoring coarse sediment particle displacement. Applied Engineering in Agriculture, 20, 783- 787.

Ockelford A and Haynes H. 2013. The impact of stress history on bed structure. Earth Surface Processes and Landforms, 38 (7), 717-727.

Olinde L and Johnson J. 2013. Characterizing coarse bedload transport during floods with RFID and accelerometer tracers, in-stream RFID antennas and HECRAS modeling. AGU Fall Meeting Abstracts.

Oldmeadow DF and Church M. 2006. A field experiment on streambed stabilization by gravel structures. Geomorphology, 78, 335-350.

Paola C. 1989. Topographic sorting, EOS Transaction American Geophysical Union, $70,332$.

Papangelakis E and Hassan M. 2016. The role of channel morphology on the mobility and dispersion of bed sediment in a small gravel-bed stream. Earth Surface Processes and Landforms.

Paphitis D and Collins MB. 2005. Sand grain threshold, in relation to bed Stress history: an experimental study. Sedimentology, 52, 827-838.

Peterson DF and Mohanty PK. 1960. Flume studies of flow in steep, rough channels. J. Hydraul. Div. Am. Soc. Civ. Eng., 86, $55-76$.

Petit F. 1987. The relationship between shear stress and the shaping of a pebbleloaded river La Rulles-Ardenne. Catena, 14, 453-468.

Phillips CB and Jerolmack DJ. 2014. Dynamics and mechanics of bed-load tracer particles. Earth Surface Dynamics, 2, 513-530. 
Phillips CB, Martin RL and Jerolmack DJ. 2013. Impulse framework for unsteady flows reveals superdiffusive bed load transport. Geophysical Research Letters, 40, 1328-1333.

Piton G and Recking A. 2017. The concept of travelling bedload and its consequences for bedload computation in mountain streams. Earth Surface Processes and Landforms.

Piton, G., Vázquez-Tarrío, D. and Recking, A. (2016). Can bed-load can help to validate hydrology studies in mountainous catchment? The case study of the Roize (Voreppe - FR). FloodRisk, Lyon, E3S Web of Conferences (Volume 7), 04020, 12 pp.

Powell DM and Ashworth PJ. 1995. Spatial pattern of flow competence and bed load transport in a divided gravel bed river. Water Resources Research, 31, 741-752.

Pyrce RS and Ashmore PE. 2003a. The relation between particle path length distributions and channel morphology in gravel-bed streams: a synthesis. Geomorphology, 56, 167-187.

Pyrce RS and Ashmore, PE. 2003b. Particle path length distributions in meandering gravel-bed streams: Results from physical models. Earth Surface Processes and Landforms, 28(9), 951-966

Pyrce RS and Ashmore PE. 2005. Bedload path length and point bar development in gravel-bed river models. Sedimentology, 52, 839-857.

Recking A, Leduc P, Liebault F and Church M. 2012. A field investigation of the influence of sediment supply on step-pool morphology and stability. Geomorphology, 139-140, 53-66. 
Recking A, Piton G, Vázquez-Tarrío D and Parker G. 2016. Quantifying the morphological print of bedload transport. Earth Surface Processes and Landforms, 41 (6), 809-822.

Reid I and Frostick LE. 1984. Particle interaction and its effect on the thresholds of initial and final bedload motion in coarse alluvial channels. In: Sedimentology of Gravels and Conglomerates, 61-68. Canadian Soc. of Petroleum Geologists Memoir 10.

Reid I, Frostick LE and Brayshaw AC. 1992. Microform roughness elements and the selective entrainment and entrapment of particles in gravel-bed rivers. In : Billi $P$, Hey RD, Thorne CR and Tacconi P. (eds). Dynamics of gravelbed rivers, Chichester: Wiley, 253-266.

Reid I, Frostick LE and Layman JT. 1985. The incidence and nature of bed load transport during flows in coarse-grained alluvial channels. Earth Surf. Processes and Landforms 10, 33-44.

Rickenmann D and Recking A. 2011. Evaluation of flow resistance in gravel-bed rivers through a large field data set. Water Resources Research , 47.

Robert A. 1997. Characteristics of velocity profiles along riffle-pool sequences and estimates of bed shear stress. Geomorphology, 19, 89-98.

Rollet AJ. 2007. Etude et gestion de la dynamique sédimentaire sur une section fluviale à l'aval d'un barrage : le cas de la basse vallée de l'Ain. Thèse de doctorat de géographie, université Lyon 3, 305 p.

Rollet AJ, MacVicar B, Piégay H, Roy AG. 2008. A comparative study on the use of passive integrated transponders to estimate sediment transport: first results (in French). La Houille Blanche 4, 110-116. 
Sawada T, Ashida K and Takahashi T. 1983. Relationship between channel pattern and sediment transport in a steep gravel bed river. Zeitschrift für. Geomorphologie Suppl., 16, $55-66$.

Schmidt KH and Ergenzinger P. 1992. Bedload entrainment, travel lengths, step lengths, rest periods - studied with passive (iron, magnetic) and active (radio) tracer techniques. Earth Surface Processes and Landforms, 17, 147-165.

Schneider J, Hegglin R, Meier S, Turowski J, Nitsche M and Rickenmann D. 2010. Studying sediment transport in mountain rivers by mobile and stationary RFID antennas. Bundesanstalt für Wasserbau: Braunschweig, Germany.

Schneider J, Turowski J, Rickenmann D, Hegglin R, Arrigo S, Mao L and Kirchner J. 2014. Scaling relationships between bed load volumes, transport distances, and stream power in steep mountain channels. Journal of Geophysical Research. Earth Surface, 119 (3), 533-549.

Sear D. 1996. Sediment transport processes in pool-riffle sequences. Earth Surface Processes and Landforms, 21, 241-262.

Sear D, Lee M, Oakley R, Carling P and Collins M. 2000. Coarse sediment tracing technology in littoral and fluvial environments: A review. In Foster IDL. (ed.) Tracers in Geomorphology. Wiley.

Seizilles G, Lajeunesse E, Devauchelle O and Bak M. 2014. Cross-stream diffusion in bedload transport. Physics of Fluids, 26.

Smith JD and McLean SR. 1984. A model for flow in meandering streams. Water Resources Research, 20 (9), 1301-1315.

Takayama S. 1965. Bedload movement in torrential mountain streams. Tokyo Geographical Paper, 9, 169-188. 
Turowski J, Yager EM, Badoux A, Rickenmann D and Molnar P. 2009. The impact of exceptional events on erosion, bedload transport and channel stability in a step-pool cannel. Earth Surface Processes and Landforms, 34 (12), 1661-1673.

Turowski JM, Badoux A and Rickenmann D. 2011. Start and end of bedload transport in gravel-bed streams. Geophysical Research Letters, 38 (4).

Vázquez-Tarrío D. 2013. Transporte de sedimento como carga de fondo en la cuenca del río Narcea (vertiente Norte de la Cordillera Cantábrica). Ph. D. Thesis. University of Oviedo, Oviedo (Spain).

Vázquez-Tarrío D and Menéndez-Duarte R. 2014. Bedload transport rates for coarse-bed streams in an Atlantic region (Narcea River, NW Iberian Peninsula). Geomorphology, 217, 1-14.

Vázquez-Tarrío D and Menéndez-Duarte R. 2015. Assessment of bedload equations using data obtained with tracers in two coarse-bed mountain streams (Narcea River basin, NW Spain). Geomorphology, 238, 78-93.

Venditti JG, Nelson PA, Minear JT, Wooster J and Dietrich WE. 2012. Alternate bar response to sediment supply termination. Journal of Geophysical Research, 117.

Venditti J, Nelson PA, Bradley RW, Haught D and Gitto AB. 2017. Bedforms, structures mobile patches and sediment supply in gravel-bedded rivers. In: Tsutsumi D and Laronne JB. (eds.). Gravel-bed rivers. Processes and disasters, WileyBlackwell, UK, PP. 439-466.

Wathen SJ. 1995. The effect of storage on sediment transfer processes in a small Scottish gravel bed river. Ph.D. thesis. St. Andrews Univ. Scotland. 289 pp.

Whiting PJ and Dietrich WE. 1991. Convective accelerations and boundary shear stress over a channel bar. Water Resources Research, 27 (5), 783-796 
Whittaker JG. 1987. Sediment transport in step-pool streams. In : Thorne CR et al. (eds.). Sediment Transport in Gravel-Bed Rivers. John Wiley, Hoboken, N. J., pp. $545-570$.

Whittaken JG and Jaeggi MNR. 1982. Origin of step-pool systems in mountain streams. J. Hydraul. Div. Am. Soc. Civ. Eng., 108, 758 - 773.

Wilcock PR. 1997. Entrainment, displacement, and transport of tracer gravels. Earth Surface Processes and Landforms, 22, 1125-1138.

Wilkinson SN, Keller RJ and Rutherford ID. 2004. Phase-shifts in shear stress as an explanation for the maintenance of pool-riffle sequences. Earth Surface Processes and Landforms, 29, 737-753.

Wilkinson SN, Rutherford ID and Keller RJ. 2008. An experimental test of whether bar instability contributes to the formation, periodicity and maintenance of pool-riffle sequences. Earth Surface Processes and Landforms, 33, 1742-1756.

Wohl EE and Grodek T. 1994. Channel bed-steps along Nahal Yael, Negev desert, Israel. Geomorphology, 9, 117-126.

Wohl EE and Thompson DM. 2000. Velocity characteristics along a small step-pool channel. Earth Surface Processes and Landforms, 25, 353 - 367.

Yager EM, Dietrich WE, Kirchner JW and McArdell BW. 2012. Prediction of sediment transport in step-pool channels. Water Ressources Research, 48 (1).

Yager EM, Turowski JM, Rickenmann D and McArdell BW. 2012. Sediment supply, grain protrusion, and bedload transport in mountain streams. Geophysical Research Letters, 39.

Yu GA, Wang ZY, Zhang K, Chang T and Liu, H. 2009. Effect of incoming sediment on the transport rate of bed load in mountain streams. International Journal of Sediment Research, 24 (3), 260-273. 
Zimmermann A and Church M. 2001. Channel morphology, gradient profiles and bed stresses during flood in a step-pool channel. Geomorphology, 40, 311- 327.

Zimmermann A, Church M and Hassan MA. 2010. Step-pool stability: testing the jammed state hypothesis. Journal of Geophysical Research. Earth Surface, 115.
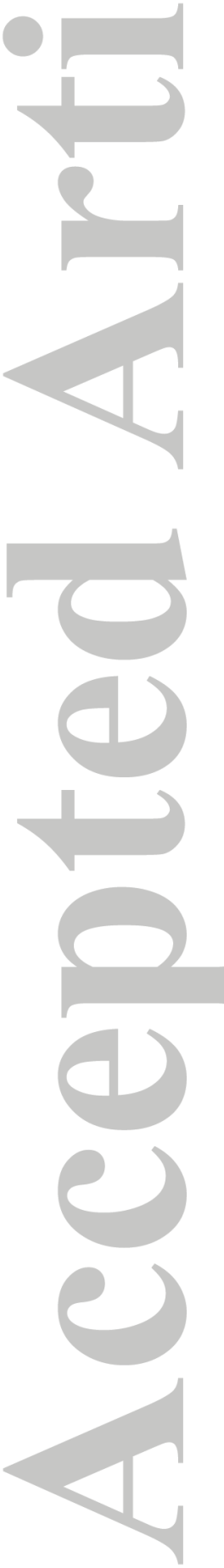
Table 1. The sources of data and information about the experiments compiled for this study. Qbf: Bankfull discharge; $\mathrm{D}_{50}$ : median size of surface sediment

\begin{tabular}{|c|c|c|c|c|c|c|c|c|c|c|}
\hline \multirow[b]{2}{*}{ Stream } & \multirow[b]{2}{*}{ Source } & \multirow[b]{2}{*}{$\begin{array}{l}\text { Qbf } \\
\left(m^{3} / s\right)\end{array}$} & \multirow[b]{2}{*}{$\begin{array}{l}\text { Channel } \\
\text { slope }\end{array}$} & \multirow[b]{2}{*}{$\begin{array}{l}D_{50} \\
(\mathrm{~mm})\end{array}$} & \multirow[b]{2}{*}{$\begin{array}{l}\text { Tagging } \\
\text { method }\end{array}$} & \multirow[b]{2}{*}{$\begin{array}{l}\text { Recovery } \\
\text { ratio (\%) }\end{array}$} & \multirow[b]{2}{*}{$\begin{array}{l}\text { Travel } \\
\text { distance } \\
\text { (m) }\end{array}$} & \multicolumn{3}{|c|}{ Available information } \\
\hline & & & & & & & & $\begin{array}{l}\text { Transport } \\
\text { distance by } \\
\text { grain size }\end{array}$ & Flow duration & Antecedent periods \\
\hline $\begin{array}{l}\text { Dry Creek } \\
\text { (USA) }\end{array}$ & Keller (1970) & - & - & - & Painted & $30-48.5$ & $44.5-65.2$ & No & Yes (graphs) & $\begin{array}{l}\text { Yes (inferred from } \\
\text { graphs) }\end{array}$ \\
\hline $\begin{array}{l}\text { White Clay } \\
\text { Creek (USA) }\end{array}$ & $\begin{array}{l}\text { Leopold and } \\
\text { Emmet (1981) }\end{array}$ & - & - & 58 & Painted & - & $10-50$ & No & No & No \\
\hline $\begin{array}{l}\text { Horse Creek } \\
\text { (USA) }\end{array}$ & Butler (1977) & - & 0.0037 & 40 & Painted & 85.7 & 84 & Yes & No & No \\
\hline $\begin{array}{l}\text { Nahal Ebron } \\
\text { (Israel) }\end{array}$ & $\begin{array}{l}\text { Hassan et al. } \\
\text { (1984); Hassan } \\
\text { (1990) }\end{array}$ & - & 0.016 & 56 & Magnets & $80-93$ & $0-65.3$ & Yes & No & No \\
\hline $\begin{array}{l}\text { Nahal Og } \\
\text { (Israel) }\end{array}$ & Hassan (1990) & - & 0.014 & 35 & Magnets & 55 & $14.2-145.8$ & Yes & No & No \\
\hline $\begin{array}{l}\text { Lainbach } \\
\text { (Germany) }\end{array}$ & $\begin{array}{l}\text { Scmidt and } \\
\text { Ergenzinger } \\
\text { (1992); Gintz et } \\
\text { al. (1996) }\end{array}$ & 30.0 & 0.02 & 120 & Iron / Magnets & $17-100$ & $4-274$ & No & Yes (table) & $\begin{array}{l}\text { Yes (inferred from } \\
\text { table) }\end{array}$ \\
\hline $\begin{array}{l}\text { North Tyne } \\
\text { (UK) }\end{array}$ & Sear (1996) & 167.0 & 0.0018 & 54 & Painted & $38-68$ & $1-87.8$ & Yes & Yes (table) & No \\
\hline Carnation & Haschenburger & - & $0.0056-$ & 47 & Magnets & $8.7-93.4$ & $25.8-129.1$ & No & Yes (table) & No \\
\hline
\end{tabular}

This article is protected by copyright. All rights reserved. 


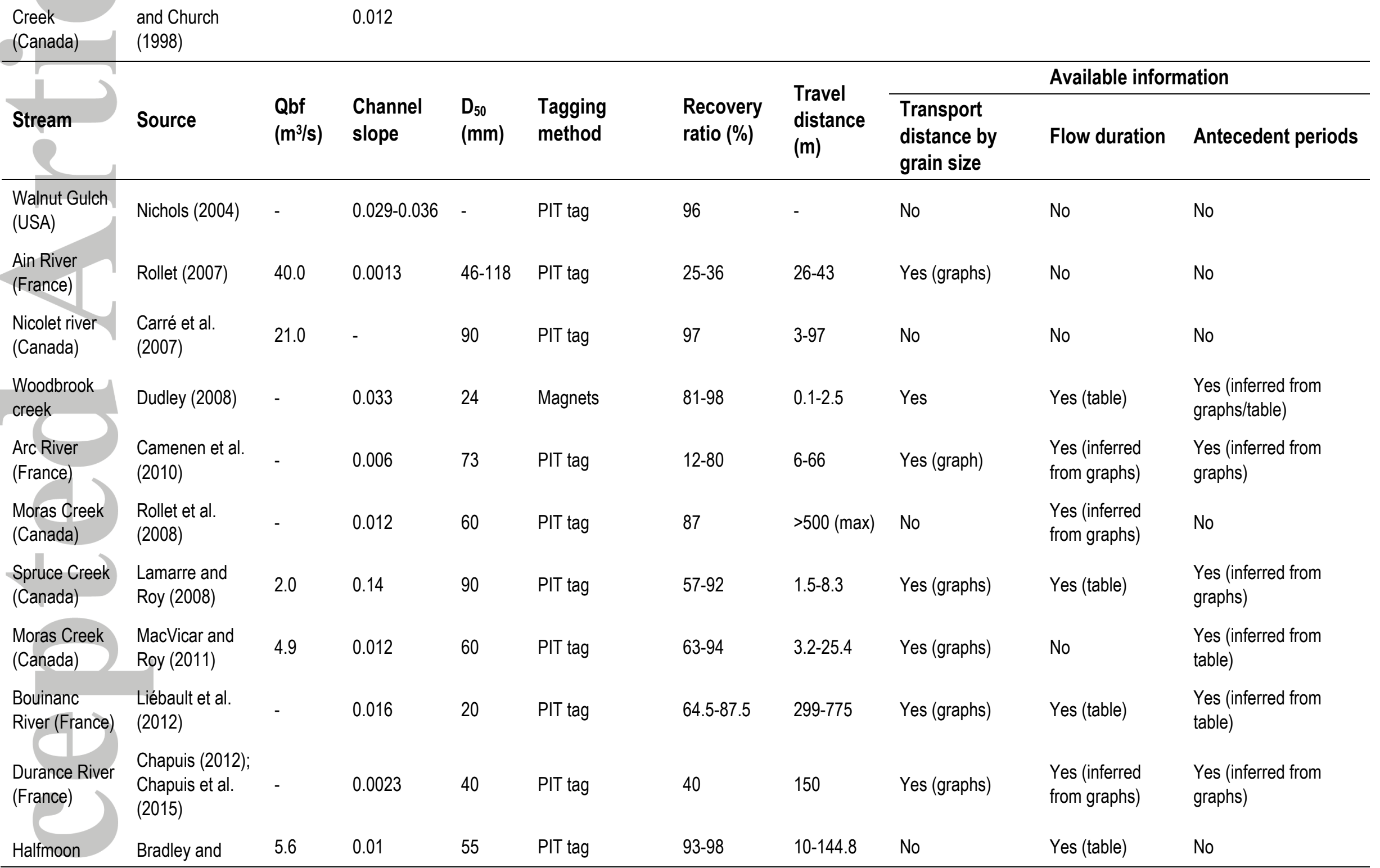

This article is protected by copyright. All rights reserved. 


\begin{tabular}{|c|c|c|c|c|c|c|c|c|c|c|}
\hline \multirow[b]{2}{*}{ Stream } & \multirow[b]{2}{*}{ Source } & \multirow[b]{2}{*}{$\begin{array}{l}\text { Qbf } \\
\left(\mathrm{m}^{3} / \mathrm{s}\right)\end{array}$} & \multirow[b]{2}{*}{$\begin{array}{l}\text { Channel } \\
\text { slope }\end{array}$} & \multirow[b]{2}{*}{$\begin{array}{l}\mathrm{D}_{50} \\
(\mathrm{~mm})\end{array}$} & \multirow[b]{2}{*}{$\begin{array}{l}\text { Tagging } \\
\text { method }\end{array}$} & \multirow[b]{2}{*}{$\begin{array}{l}\text { Recovery } \\
\text { ratio (\%) }\end{array}$} & \multirow[b]{2}{*}{$\begin{array}{l}\text { Travel } \\
\text { distance } \\
\text { (m) }\end{array}$} & \multicolumn{3}{|c|}{ Available information } \\
\hline & & & & & & & & $\begin{array}{l}\text { Transport } \\
\text { distance by } \\
\text { grain size }\end{array}$ & Flow duration & Antecedent periods \\
\hline $\begin{array}{l}\text { Rede River } \\
\text { (UK) }\end{array}$ & Milan $(2013 a, b)$ & - & 0.006 & $52-109$ & PIT tag & 43-92 & & Yes & Yes (table) & No \\
\hline $\begin{array}{l}\text { Erlenbach } \\
\text { (Switzerland) }\end{array}$ & $\begin{array}{l}\text { Schneider et al. } \\
(2014)\end{array}$ & $\sim 2.0$ & 0.15 & 64 & PIT tag/Magnetic & $24-91$ & $7-161$ & Yes (graphs) & No & $\begin{array}{l}\text { Yes (inferred from } \\
\text { table) }\end{array}$ \\
\hline $\begin{array}{l}\text { Rio Cordon } \\
\text { (Italy) }\end{array}$ & $\begin{array}{l}\text { Schneider et al. } \\
(2014)\end{array}$ & - & 0.13 & 90 & Magnetic & $52-100$ & $1-142$ & Yes (graphs) & No & $\begin{array}{l}\text { Yes (inferred from } \\
\text { table) }\end{array}$ \\
\hline $\begin{array}{l}\text { Pigüeña River } \\
\text { (Spain) }\end{array}$ & $\begin{array}{l}\text { Vázquez-Tarrío } \\
\text { and Menéndez- } \\
\text { Duarte (2014) }\end{array}$ & 70.0 & 0.007 & 56 & Painted/Magnetic & $11-77$ & $6-66$ & Yes (graphs) & Yes (table) & $\begin{array}{l}\text { Yes (inferred from } \\
\text { table) }\end{array}$ \\
\hline $\begin{array}{l}\text { Coto River } \\
\text { (Spain) }\end{array}$ & $\begin{array}{l}\text { Vázquez-Tarrío } \\
\text { and Menéndez- } \\
\text { Duarte (2014) }\end{array}$ & 17.0 & 0.01 & 88 & Painted/Magnetic & $17-20$ & $11-19$ & Yes (graphs) & Yes (table) & $\begin{array}{l}\text { Yes (inferred from } \\
\text { table) }\end{array}$ \\
\hline $\begin{array}{l}\text { Aisne River } \\
\text { (Belgium) }\end{array}$ & $\begin{array}{l}\text { Houbrechts et } \\
\text { al. }(2015)\end{array}$ & 23.8 & 0.0053 & 92 & PIT tag & $62-97$ & $1-271$ & No & No & $\begin{array}{l}\text { Yes (inferred from } \\
\text { table) }\end{array}$ \\
\hline $\begin{array}{l}\text { Strimm Creek } \\
\text { (Italy) }\end{array}$ & $\begin{array}{l}\text { Dell'Agnese et } \\
\text { al. (2015) }\end{array}$ & - & $0.08-0.15$ & $\begin{array}{l}62.3- \\
76.1\end{array}$ & PIT tag & $54.7-97.7$ & $1-580$ & Yes (graphs) & $\begin{array}{l}\text { Yes (inferred } \\
\text { from graphs) }\end{array}$ & $\begin{array}{l}\text { Yes (inferred from } \\
\text { graphs) }\end{array}$ \\
\hline $\begin{array}{l}\text { Wilket Creek } \\
\text { (Canada) }\end{array}$ & $\begin{array}{l}\text { MacVicar et al. } \\
(2015)\end{array}$ & - & 0.012 & $58-115$ & PIT tag & $81-89$ & $3-55$ & Yes (graphs) & No & $\begin{array}{l}\text { Yes (inferred from } \\
\text { table) }\end{array}$ \\
\hline $\begin{array}{l}\text { East Creek } \\
\text { (Canada) }\end{array}$ & $\begin{array}{l}\text { Papangelakis } \\
\text { and Hassan } \\
(2016)\end{array}$ & 2.0 & $0.018-0.02$ & $49-55$ & Magnets & $77-88$ & $0.25-36$ & Yes (graphs) & No & No \\
\hline
\end{tabular}

This article is protected by copyright. All rights reserved. 
Table 2. Summary of the correlations between tracer travel distance and dimensionless peak stream power. Correlations that were statistically significant (95\% thrust level) are highlighted in bold characters. N: number of data. SP: Step-pool. RP: Riffle and Pool. PB: Plane-bed. In this paper, power law fitting was always done in the same way: log-transforming the response and predictor variables, and doing an ordinary (linear) least squares fit.

\begin{tabular}{|c|c|c|c|c|c|c|}
\hline \multirow{2}{*}{ Data set } & \multicolumn{3}{|c|}{ Mean travel distances } & \multicolumn{3}{|c|}{ Mean scaled travel distances } \\
\hline & $R^{2}$ & $\mathrm{p}$-value & $\mathrm{N}$ & $R^{2}$ & p-value & $\mathrm{N}$ \\
\hline All & 0.25 & 0.00 & 78 & 0.30 & 0.00 & 78 \\
\hline SP : All & 0.24 & 0.02 & 32 & 0.52 & 0.00 & 32 \\
\hline 'Constrained' & 0.76 & 0.00 & 16 & 0.83 & 0.00 & 16 \\
\hline 'Unconstrained' & 0.22 & 0.03 & 16 & 0.42 & 0.00 & 16 \\
\hline $\mathrm{RP}+\mathrm{MT}: \mathrm{All}$ & 0.40 & 0.00 & 31 & 0.72 & 0.00 & 31 \\
\hline 'Constrained' & 0.44 & 0.00 & 26 & 0.72 & 0.00 & 26 \\
\hline 'Unconstrained' & 0.09 & 0.63 & 5 & 0.52 & 0.17 & 5 \\
\hline PB : All & 0.68 & 0.00 & 15 & 0.66 & 0.00 & 15 \\
\hline 'Constrained' & 0.68 & 0.00 & 12 & 0.65 & 0.00 & 12 \\
\hline 'Unconstrained' & 0.99 & 0.06 & 3 & 0.99 & 0.06 & 3 \\
\hline
\end{tabular}




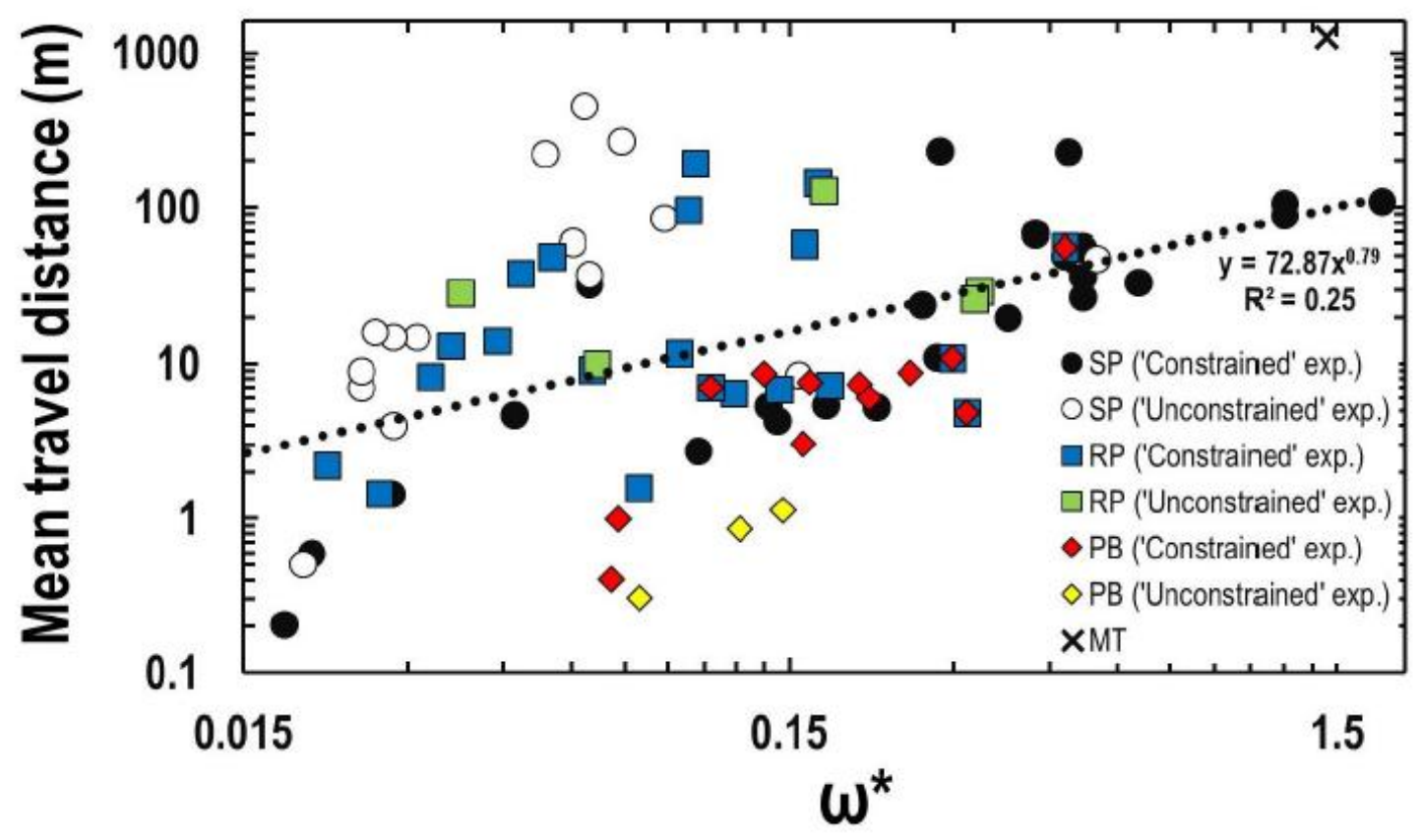

Figure 1. Mean travel distance of tracer population versus dimensionless peak stream power of the transport episode. Data were fitted to a power law.

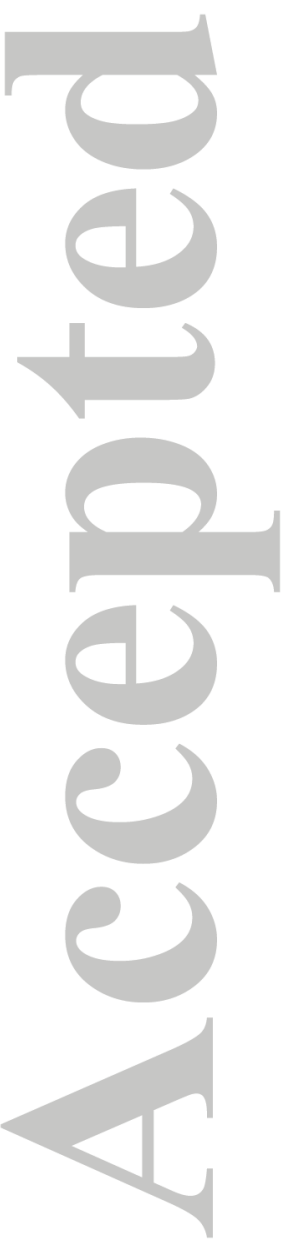



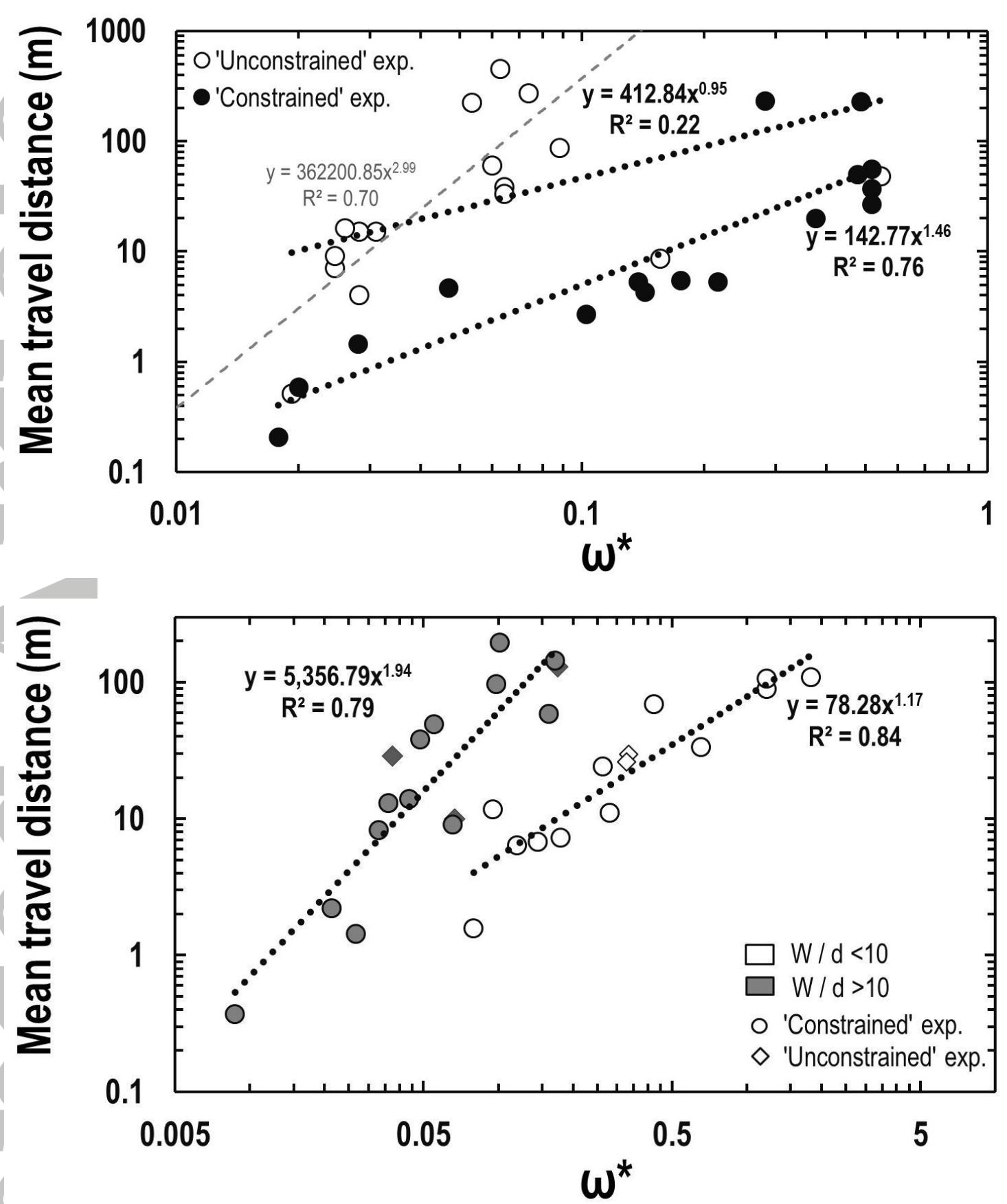

Figure 2. Mean travel distance of tracer population versus dimensionless peak stream power of the transport episode for: A) step-pool data, and B) riffle and pool data. Sources of data: SP (Dell'Agnese et al., 2015; Dudley, 2007; Gintz et al., 1996; Schmidt and Ergenzinger, 1992; Schneider et al., 2014); RP (Bradley and Tucker, 2012; Haschenburger and Church, 1998; Houbrechts et al., 2015; Papangelakis and Hassan; 2016). Dark lines in figure 2A represent the best power-law fit found for each data set (constrained and unconstrained SP data), considering all data points in the regression; grey line represent the best power-law fit for unconstrained SP data, excluding 2 outliers. 


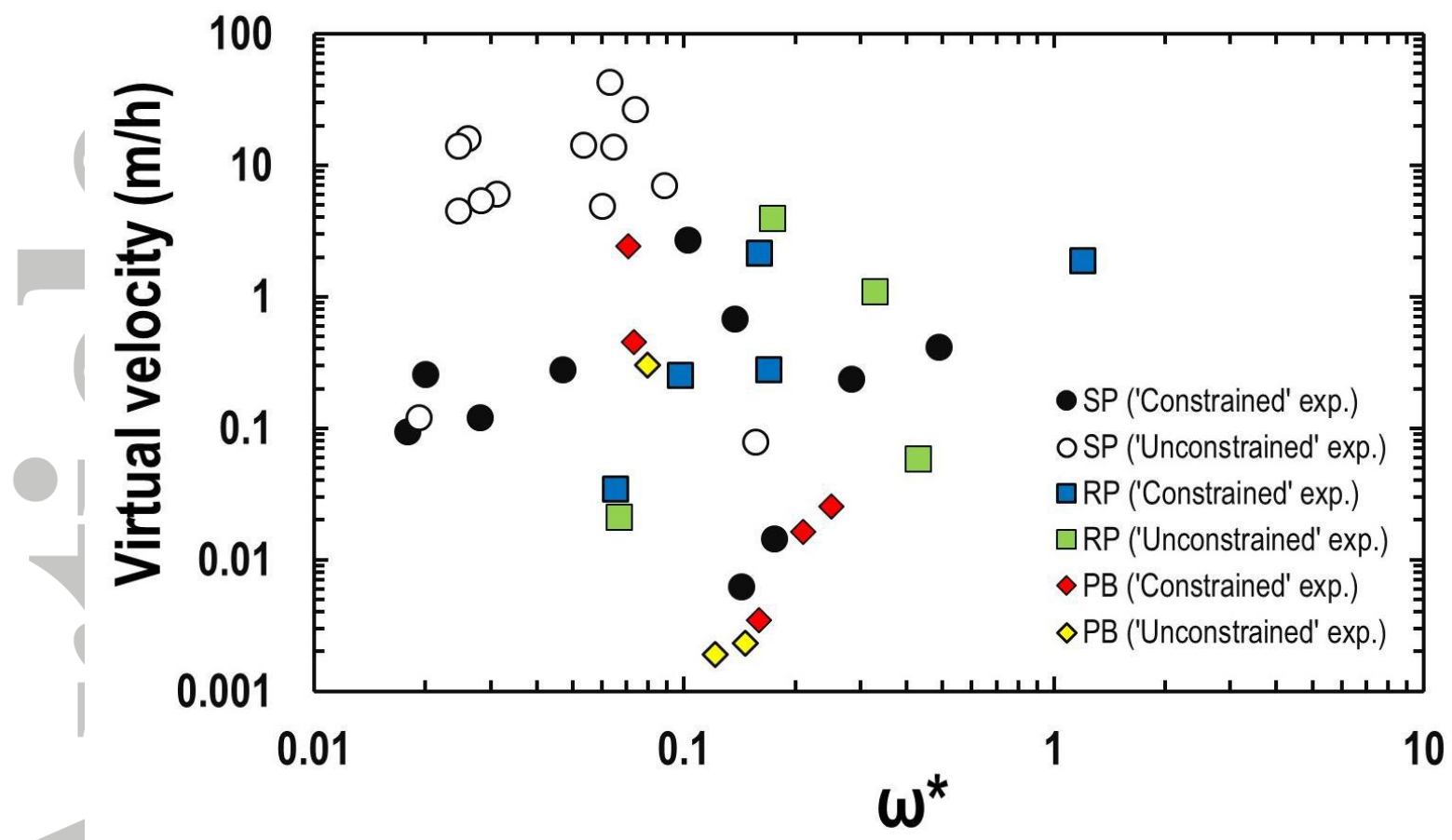

Figure 3. Virtual velocity of tracer dispersion plotted against dimensionless peak stream power.

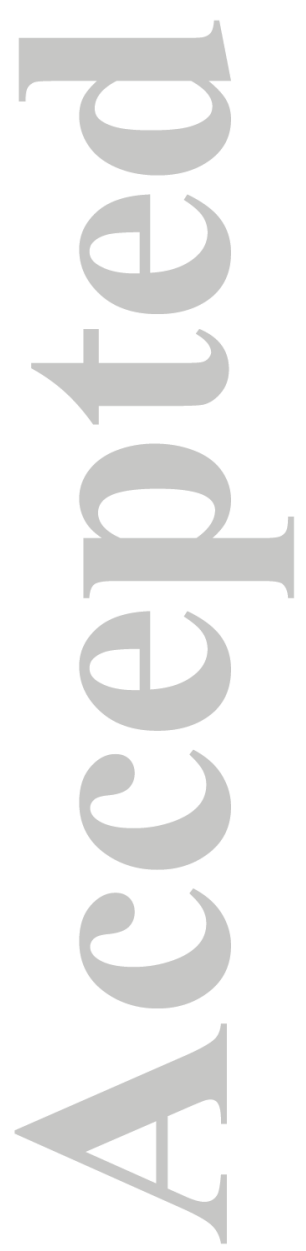




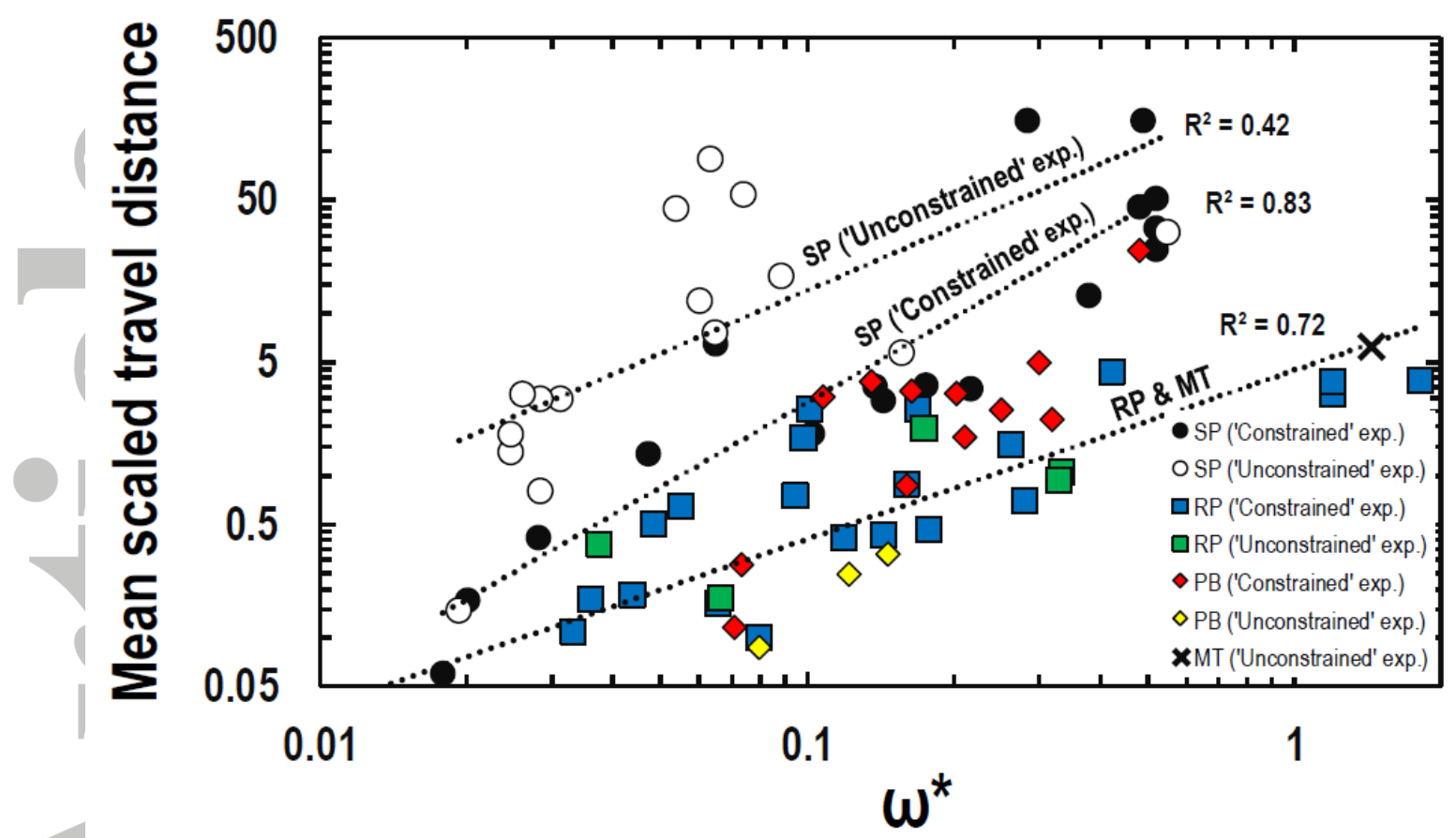

Figure 4. Mean tracer travel distances normalized by the 'morphological length' of channel versus dimensionless peak stream power. Data were fitted to power laws.

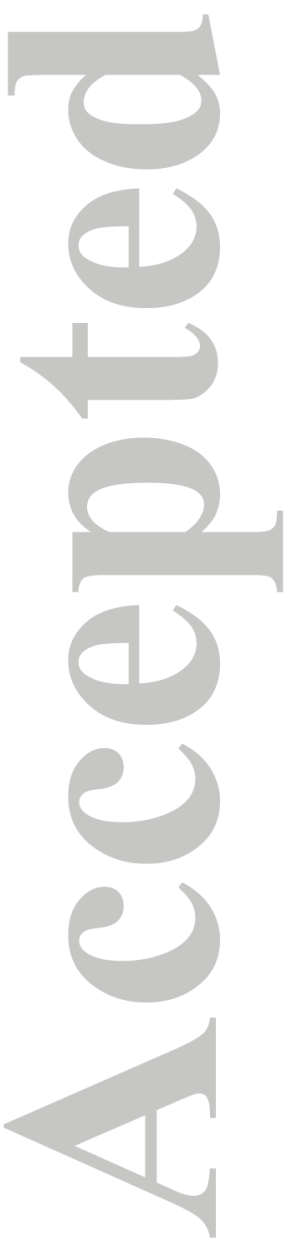




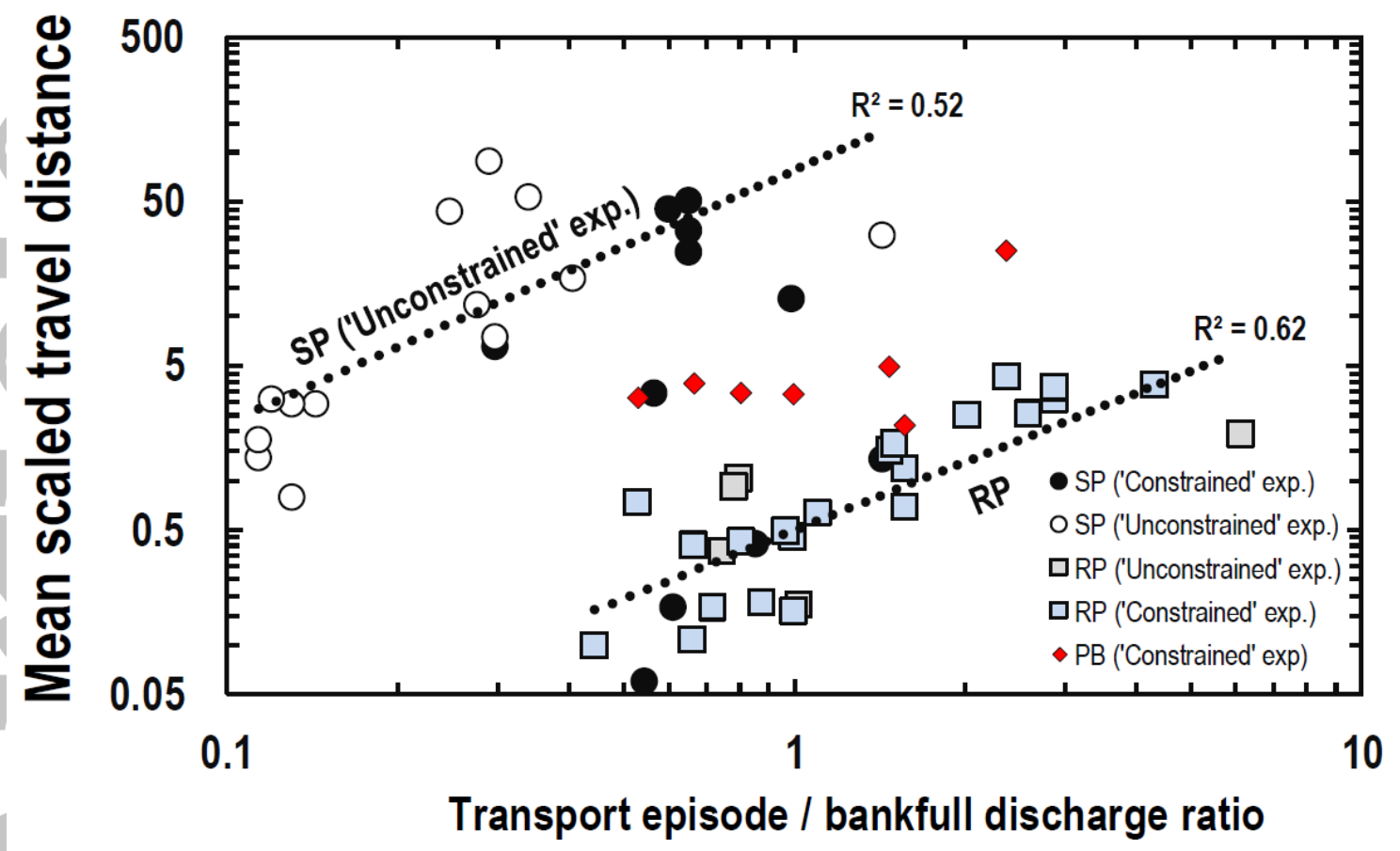

Figure 5. Mean tracer travel distances normalized by the 'morphological length' of channel plotted versus the ratio of discharge of the transport episode to bankfull discharge. Data were fitted to power laws. There are not unconstrained data for PB in this plot because there were not available data of bankfull discharge for this group of experiments. 


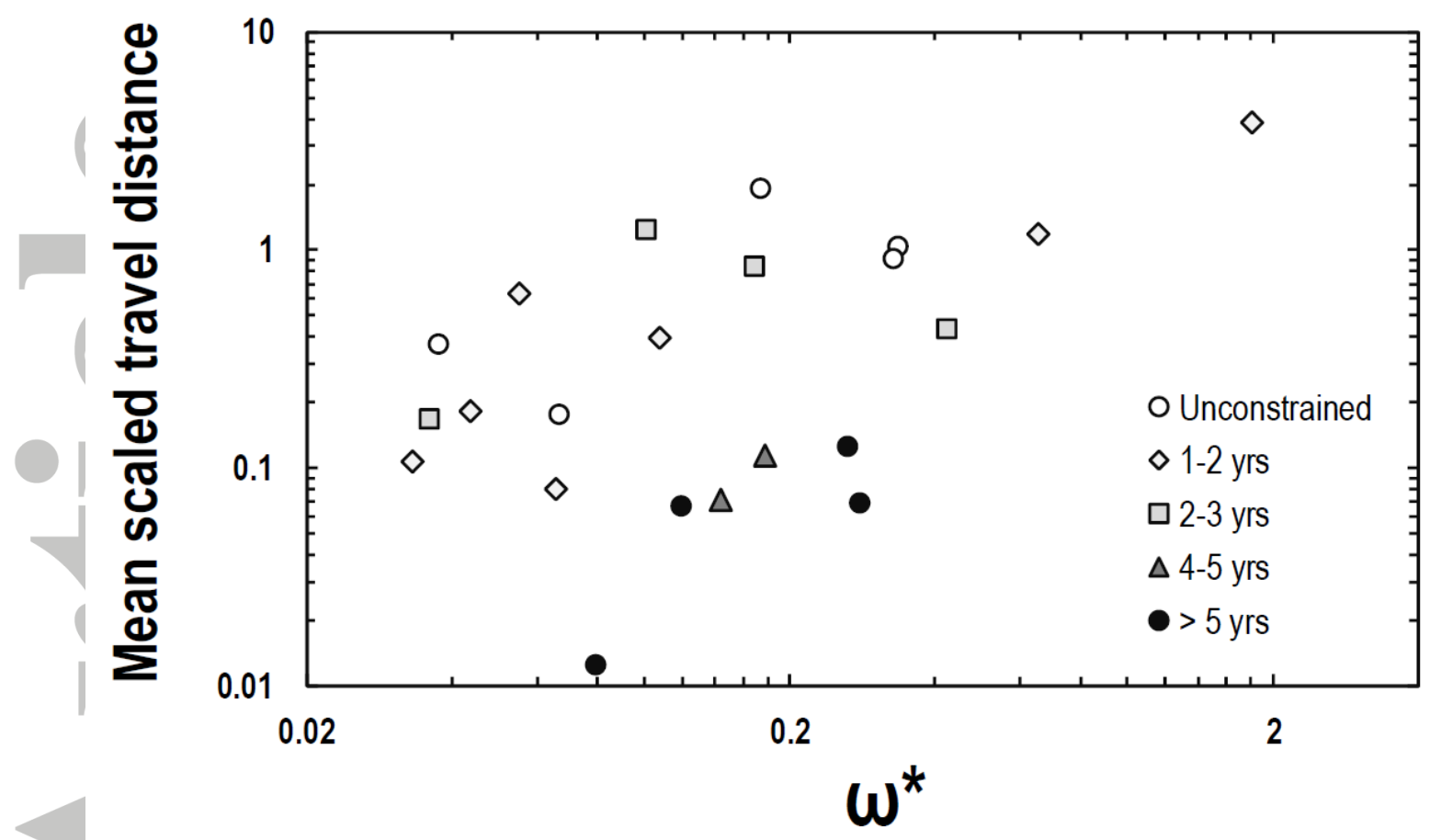

Figure 6. Mean scaled travel distance plotted against the peak specific stream power. Data were grouped according to 'tracer age': time passing from tracer deployment to tracer survey. 


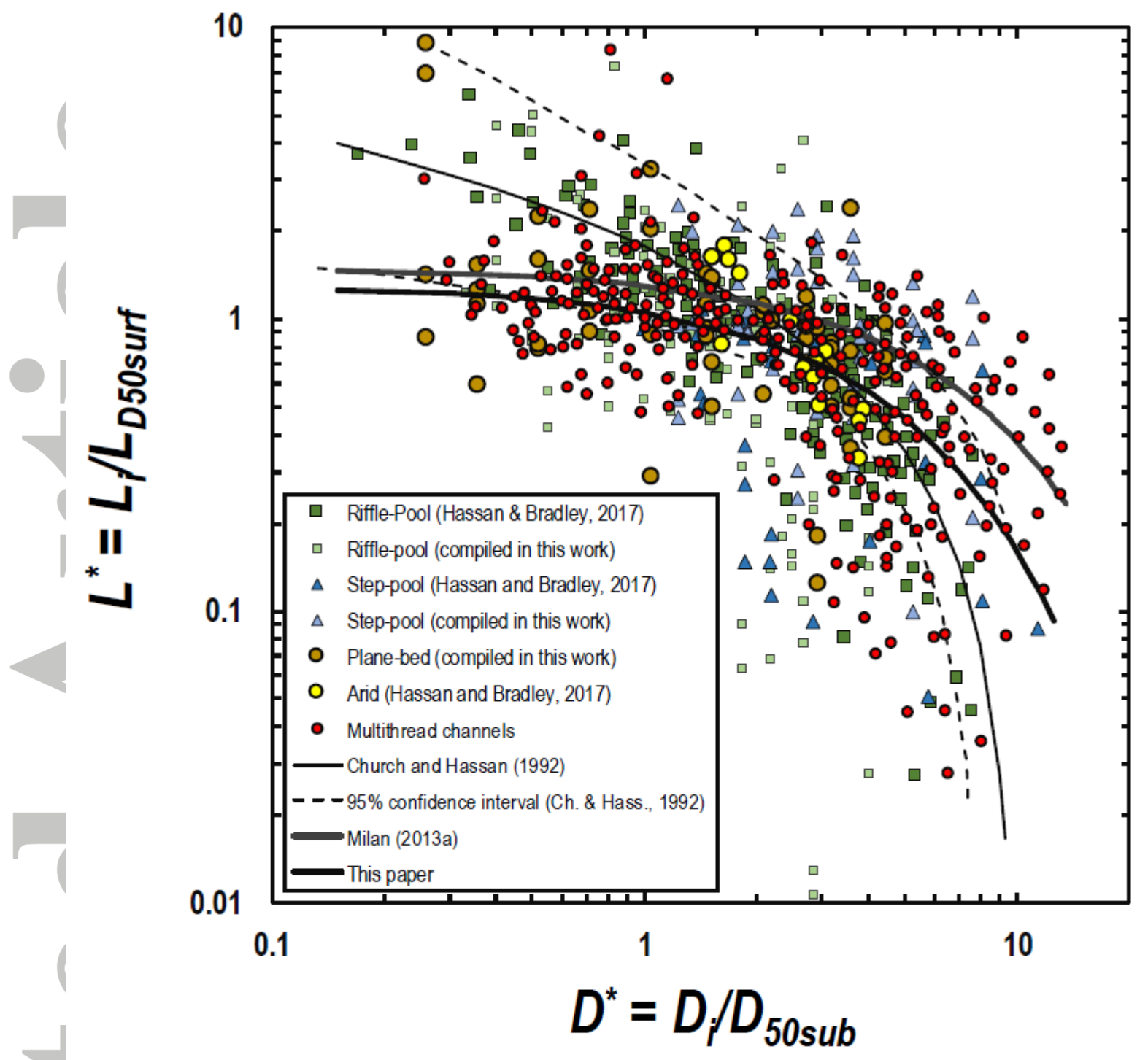

Figure 7. Scaled travel distance of individual particles as a function of scaled particle size. The travel distance of each size fraction $\left(L_{i}\right)$ is scaled by the travel distance of the size class that includes the median size of the bed-surface sediment $\left(L D_{50 \text { sur }}\right)$. Tracer size is scaled $\left(D_{i}\right)$ by the median size of the subsurface grain size distribution $\left(D_{50 \text { sub }) \text {. }}\right.$ 


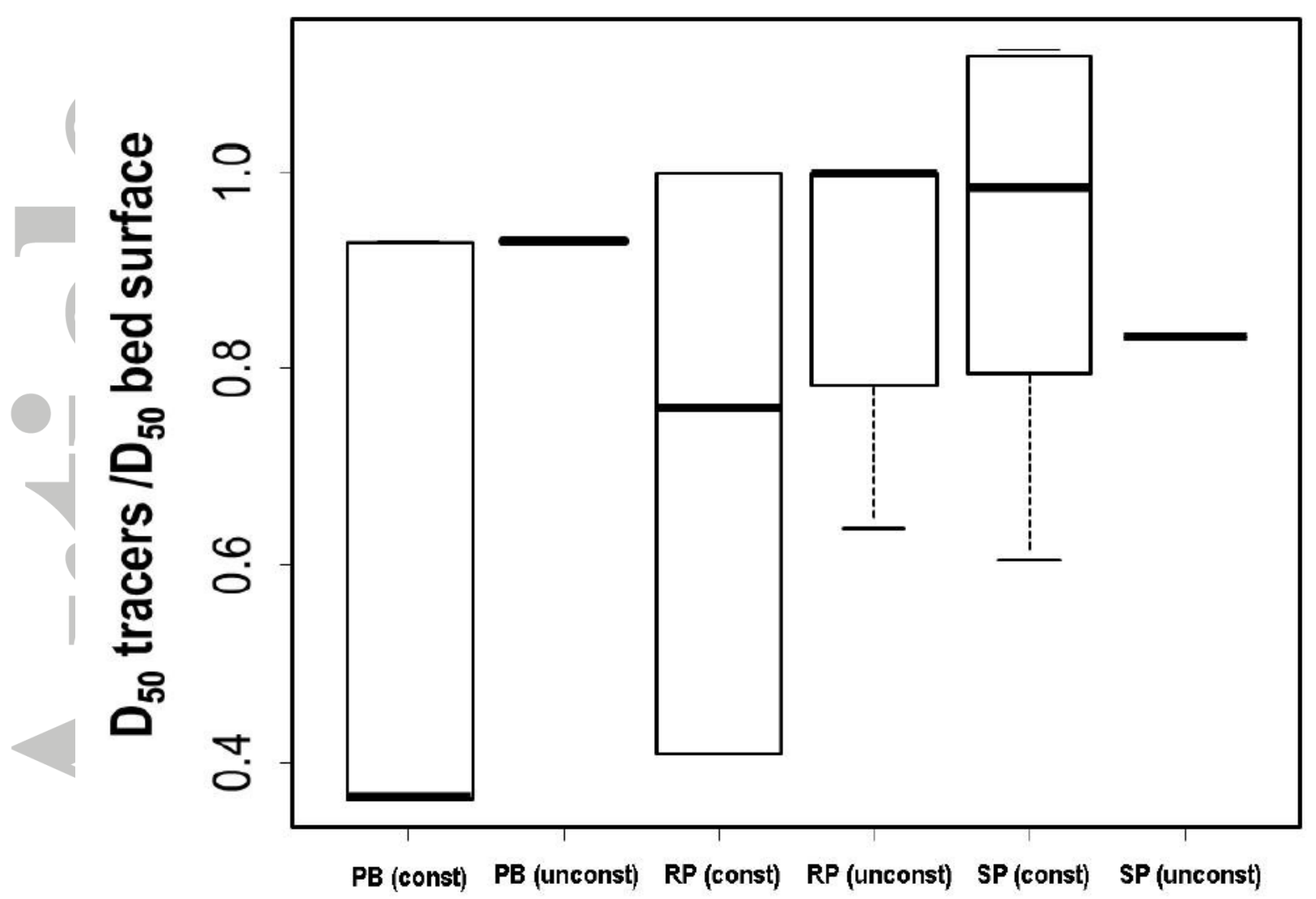

Figure 8. Median tracer size relative to bed surface $D_{50}$ for the different group of data. 


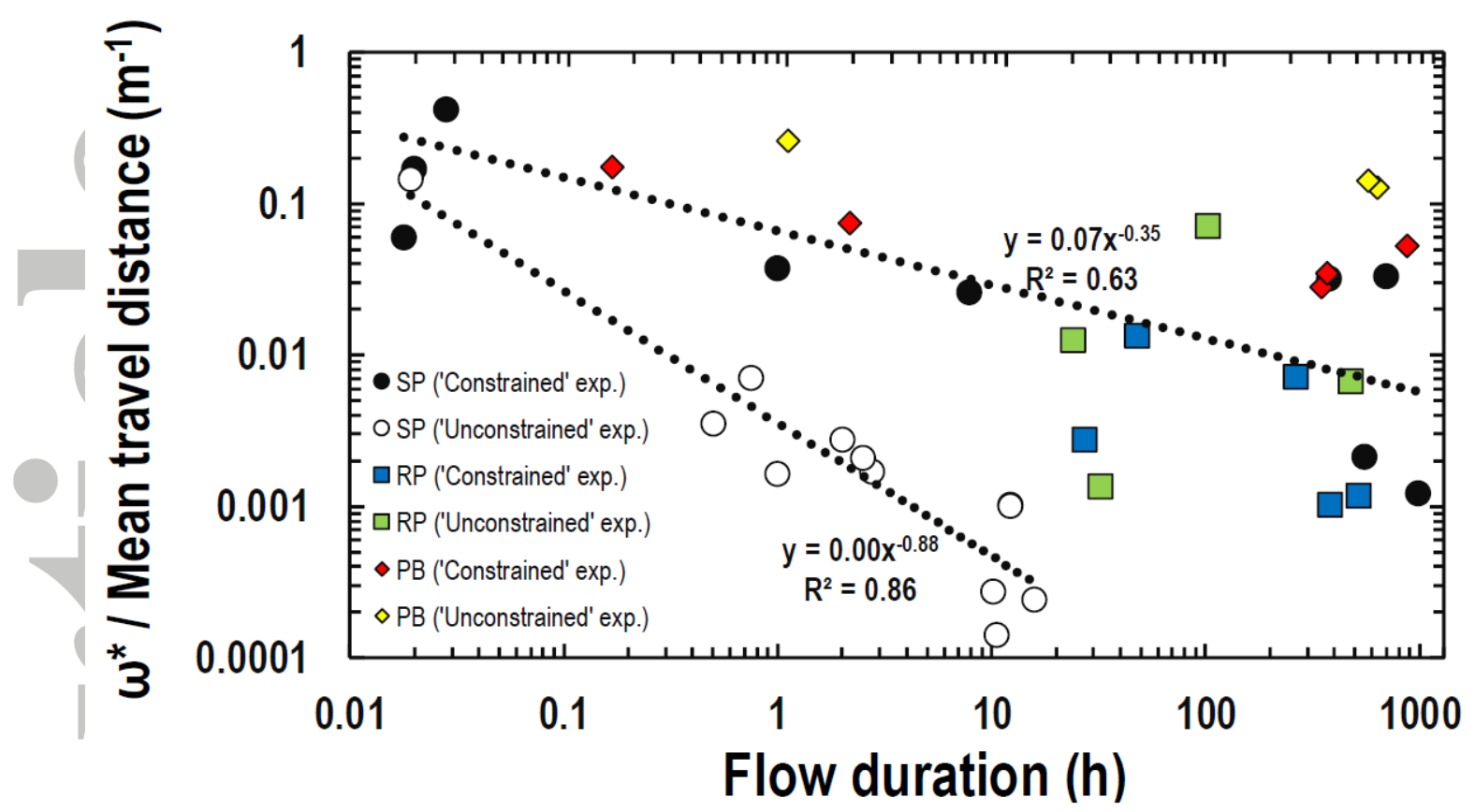

Figure 9. The ratio of dimensionless peak specific stream power to scaled travel distance plotted against flow duration.

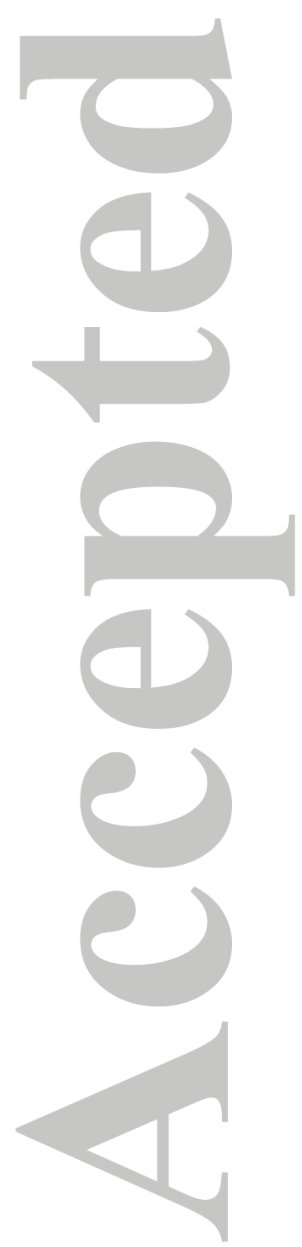




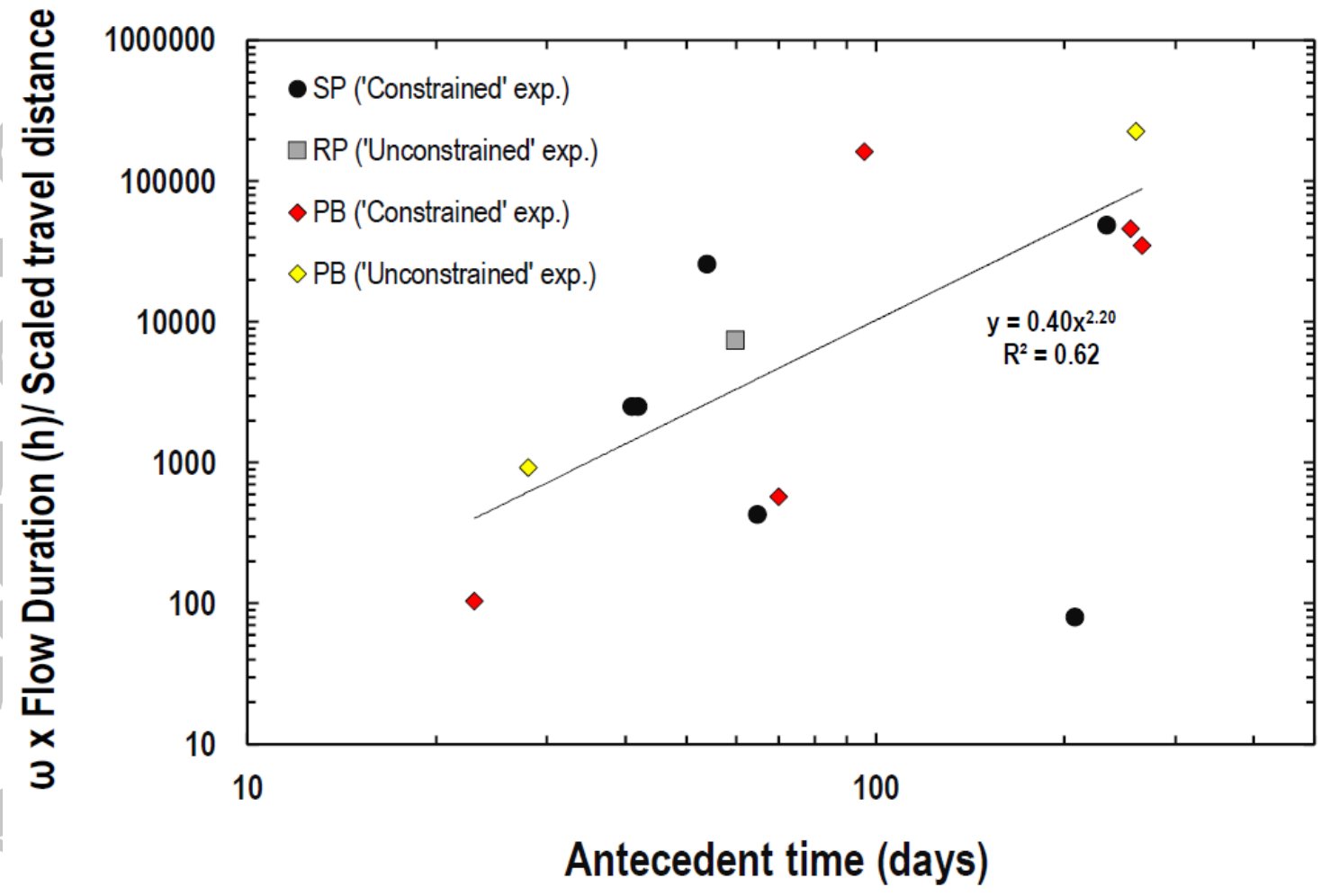

Figure 10. Ratio of dimensionless peak specific stream power (times flow duration) to scaled travel distance plotted against the time elapsed between tracer seeding and tracer movement or subsequent transport episodes. There are not unconstrained data for SP channels and constrained data for RP channels in this plot because there were not available data of antecedent time for these groups of experiments. 

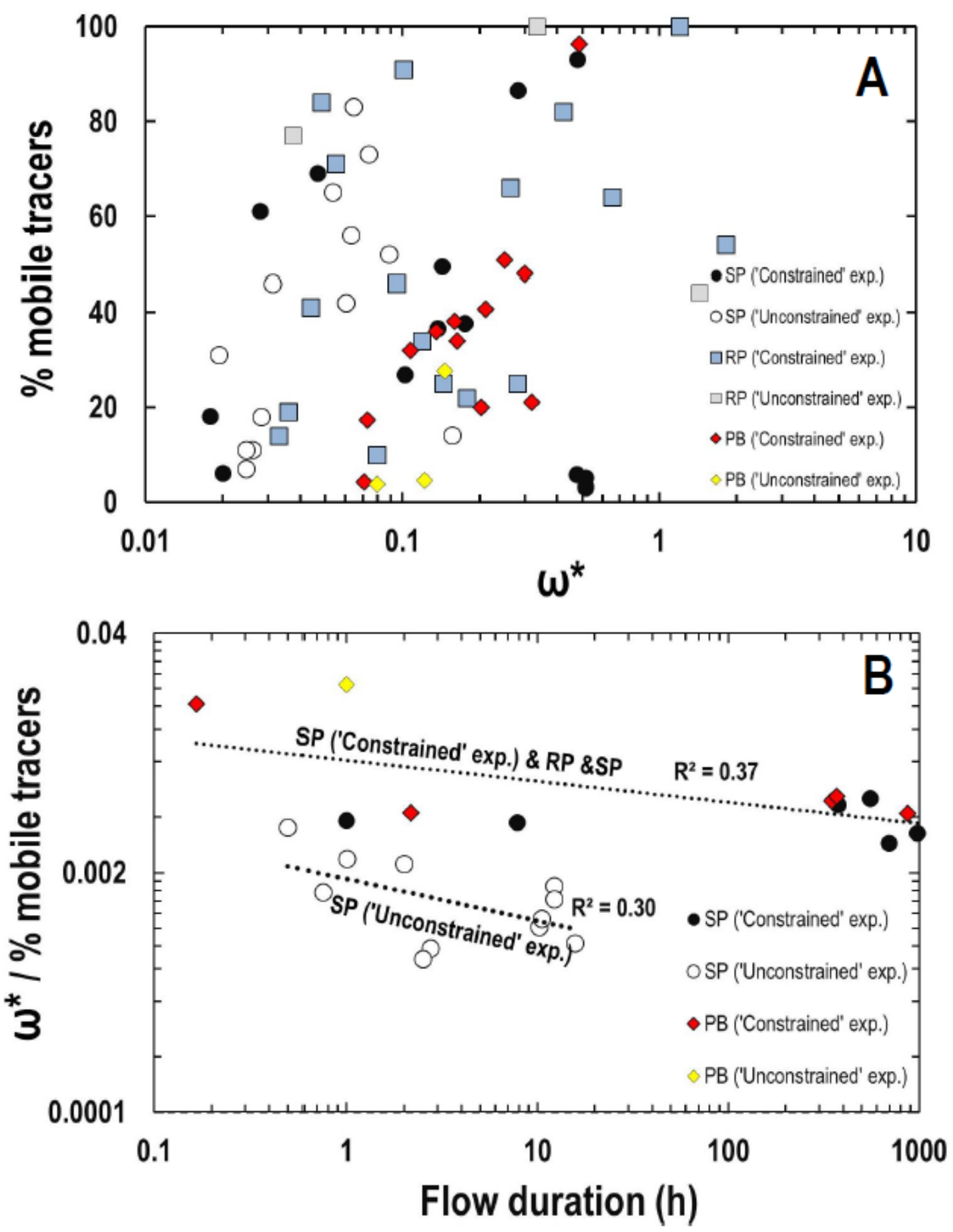

Figure 11. A) Percentage of mobile tracers plotted against dimensionless peak stream power. B) Ratio of dimensionless peak specific stream power to percentage of mobile tracers plotted against flow duration. 


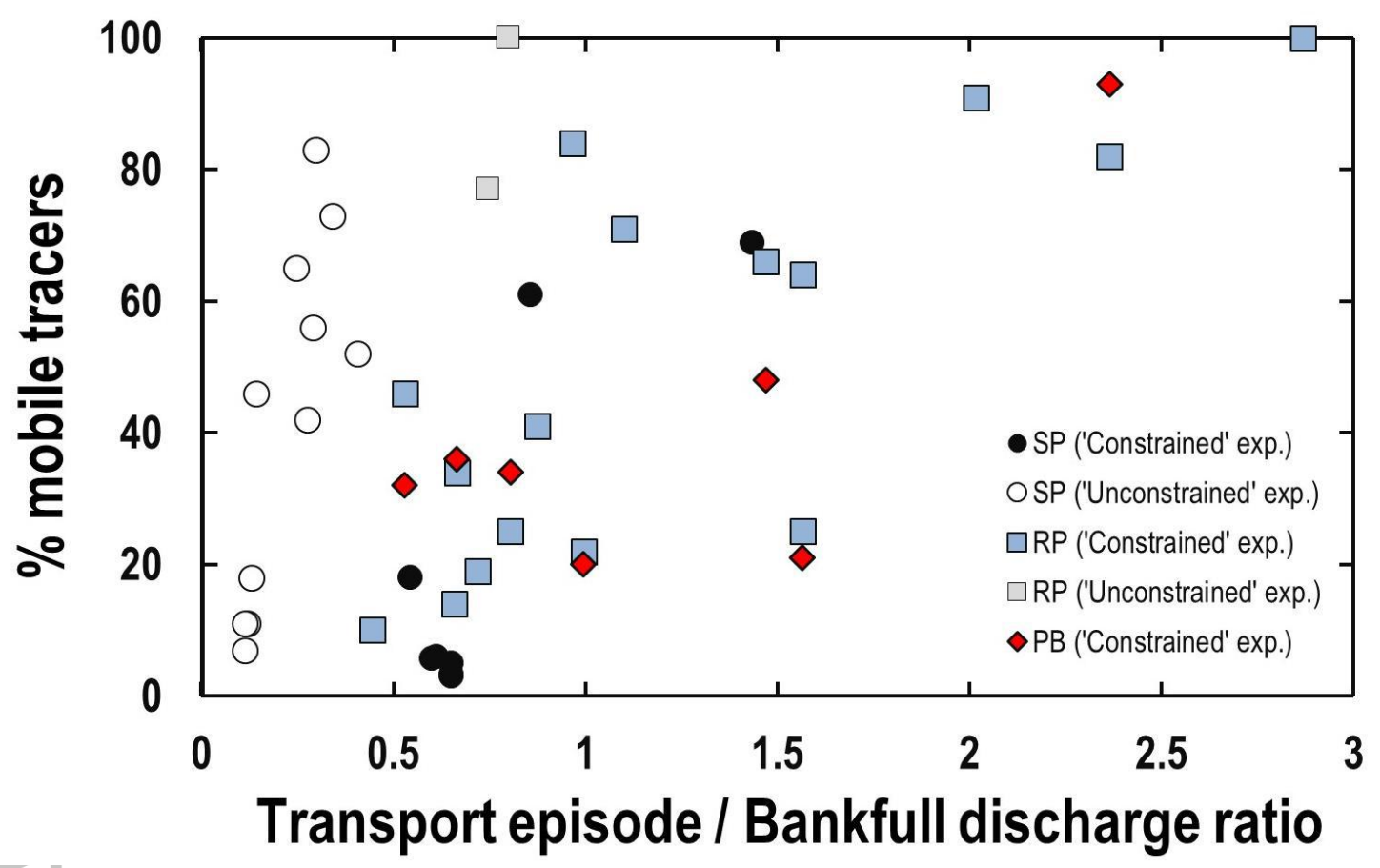

Figure 12. Percentage of mobilised tracers versus the transport episode/ bankfull discharge ratio.

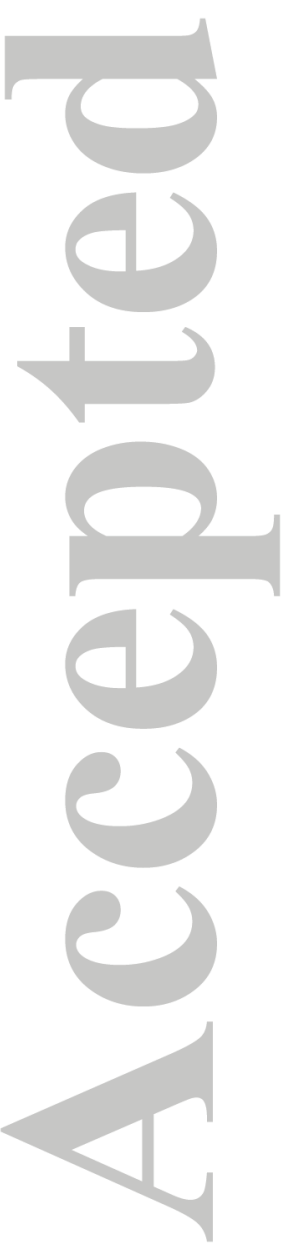




\section{Particle transport in gravel-bed rivers: revisiting passive tracer data}

Daniel Vázquez-Tarrío*, Alain Recking, Frédéric Liébault, Michal Tal, Rosana Menéndez-Duarte

Data on river gravel transport coming from previously published tracer experiments are critically reviewed and evaluated accounting for channel morphology and experimental conditions. Different patterns of particle transport between step- and riffle-pool channels were found.

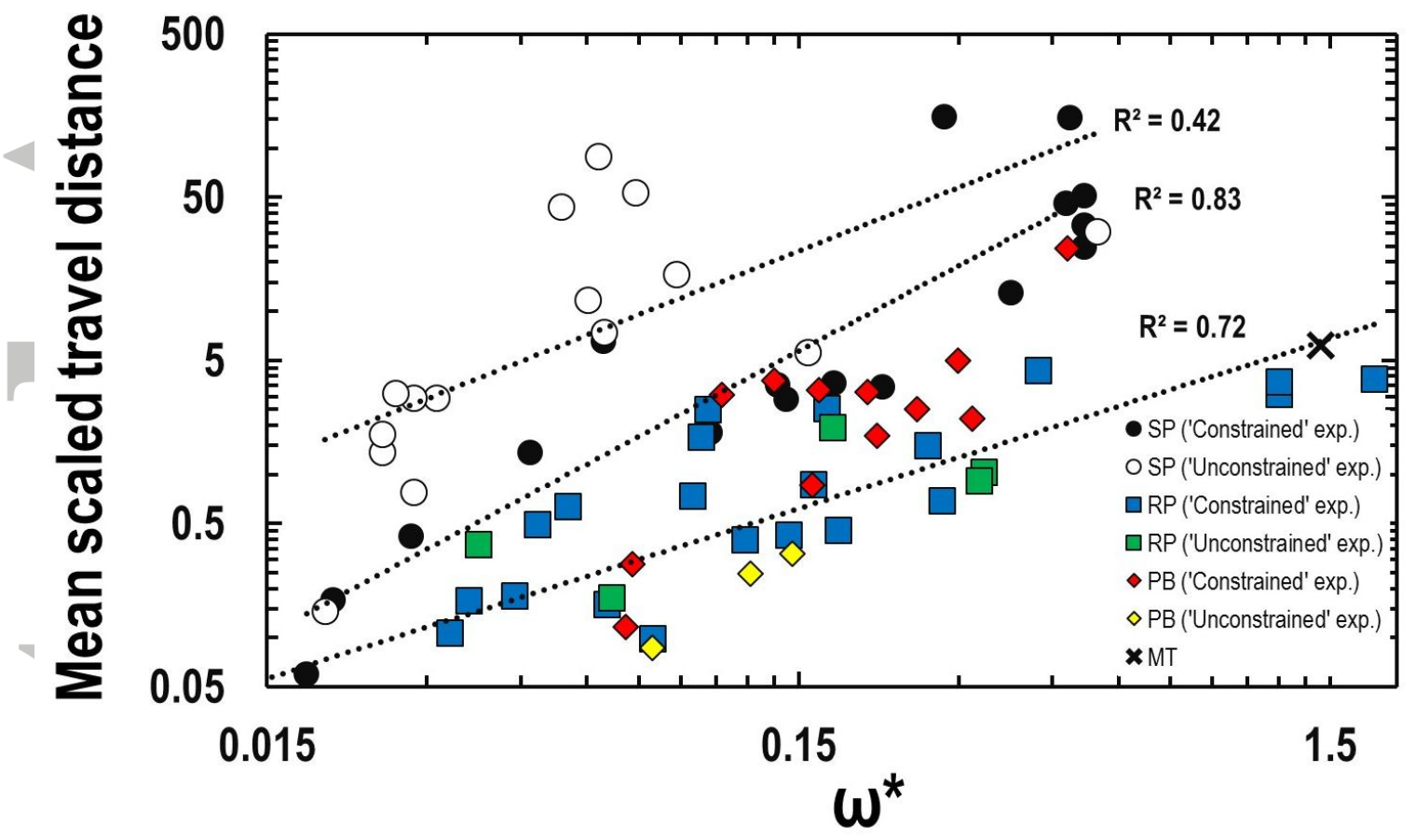

